\title{
Simulating Collisions for Hydrokinetic Turbines
}

\author{
MC Richmond \\ PDJ Romero-Gomez \\ CL Rakowski
}

Hydrology Group

Pacific Northwest National Laboratory

Richland, WA 99352

October 2013

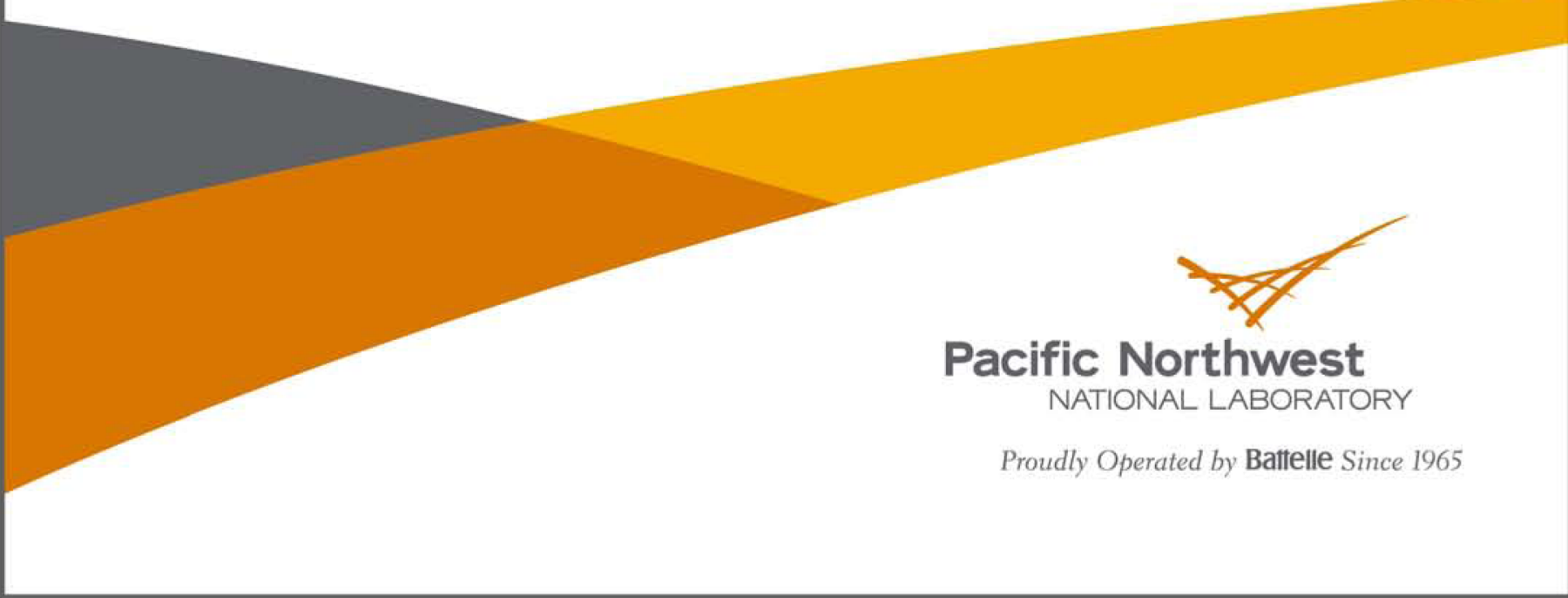




\title{
DISCLAIMER
}

United States Government. Neither the United States Government nor any agency thereof, nor Battelle Memorial Institute, nor any of their employees, makes any warranty, express or implied, or assumes any legal liability or responsibility for the accuracy, completeness, or usefulness of any information, apparatus, product, or process disclosed, or represents that its use would not infringe privately owned rights. Reference herein to any specific commercial product, process, or service by trade name, trademark, manufacturer, or otherwise does not necessarily constitute or imply its endorsement, recommendation, or favoring by the United States Government or any agency thereof, or Battelle Memorial Institute. The views and opinions of authors expressed herein do not necessarily state or reflect those of the United States Government or any agency thereof.

\author{
PACIFIC NORTHWEST NATIONAL LABORATORY \\ operated by \\ BATTELLE \\ for the \\ UNITED STATES DEPARTMENT OF ENERGY \\ under Contract DE-AC05-76RLO1830
}

\author{
Printed in the United States of America \\ Available to DOE and DOE contractors from the \\ Office of Scientific and Technical Information, \\ P.O. Box 62, Oak Ridge, TN 37831-0062; \\ ph: (865) 576-8401 \\ fax: $\quad(865)$ 576-5728 \\ email: reports@adonis.osti.gov

\footnotetext{
Available to the public from the National Technical Information Service, U.S. Department of Commerce, 5285 Port Royal Rd., Springfield, VA 22161 ph: $\quad(800)$ 553-6847 fax: (703) 605-6900

email: orders@ntis.fedworld.gov

online ordering: http://www.ntis.gov/ordering.htm
} \\ This document was printed on recycled paper. \\ $(9 / 2003)$
}


PNNL-22580

\section{Simulating Collisions for Hydrokinetic Turbines}

MC Richmond

PDJ Romero-Gomez

CL Rakowski

Hydrology Group

Pacific Northwest National Laboratory

Richland, WA 99352 



\begin{abstract}
Evaluations of potential blade-strike on an axial-flow marine hydrokinetic (MHK) turbine were conducted using a method that integrates the following components into a computational fluid dynamics (CFD) model: (i) advanced eddy-resolving flow simulations, (ii) inflow turbulence based on field data, (iii) moving turbine blades in a transient flow, and (iv) Lagrangian particles to represent fish. The sensitivity of blade-strike probability to the following conditions was also evaluated: (i) turbulent environment, (ii) fish particle size and (iii) mean stream flow velocity. A limitation of the method is that fish are represented as particles that simply move with the fluid and can exhibit no behavioral response such as avoidance of the MHK turbine. This limitation causes a tendency for the model to overestimate strikes since it is likely that some fraction of an approaching population of fish would actively avoid the turbine.

The CFD-based blade strike simulations provide not only the frequency of collisions, but also insights into the causal relationships between the flow environment and resulting particle strikes on rotating blades. The results were compared against the outcomes of a conventional method that only considers the kinematic aspects of the fish passage event without any regard for the flow dynamics. Overall, the conventional method, while simple to apply, largely overestimates the probability of strike, and lacks the ability to produce potential fish and aquatic biota trajectories as they interact with the rotating turbine. In contrast the CFD-based Lagrangian method utilizes a set of experimental correlations of exposure-response of live fish colliding on moving blades, frequency of occurrence, intensity of the particle collisions to calculate the estimated survival rate of fish encountering the MHK turbine. Estimated survival rates were greater than $96 \%$, which are comparable to or better than many conventional hydropower turbines. Although the proposed CFD framework is computationally more expensive, it provides the advantage of evaluating multiple mechanisms of stress and injury of hydrokinetic turbine devices on fish and relating those to specific design features of the MHK turbine.
\end{abstract}





\section{Acknowledgments}

Support for this research was provided by the U.S. Department of Energy, Office of Energy Efficiency and Renewable Energy - Wind and Water Power Program. The authors would like to thank Matthew Barone, Erick Johnson, and Rich Jepsen of Sandia National Laboratories for providing the turbine geometry and the results of their blade element method (BEM) calculations. 



\section{Abbreviations and Acronyms}

$\begin{array}{ll}\text { ABBREV } & \text { DEFINITION } \\ \text { BEM } & \text { blade element method } \\ \text { CFD } & \text { computational fluid dynamics } \\ \text { DES } & \text { detached eddy simulation } \\ \text { DNS } & \text { direct numerical simulation } \\ \text { FERC } & \text { Federal Energy Regulatory Commission } \\ \text { MHK } & \text { marine hydrokinetic } \\ \text { RBM } & \text { rigid-body motion } \\ \text { RPM } & \text { revolutions per minute } \\ \text { RPS } & \text { revolutions per second } \\ \text { SEM } & \text { synthetic eddy method } \\ \text { TSR } & \text { tip speed ratio } \\ \text { URANS } & \text { unsteady-state Reynolds-averaged Navier-Stokes }\end{array}$





\section{Contents}

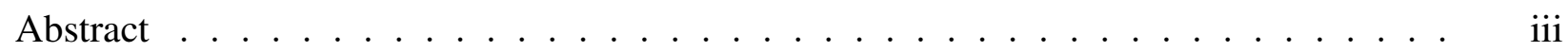

Acknowledgments ..........................

Abbreviations and Acronyms $\ldots \ldots \ldots \ldots \ldots \ldots$ vii

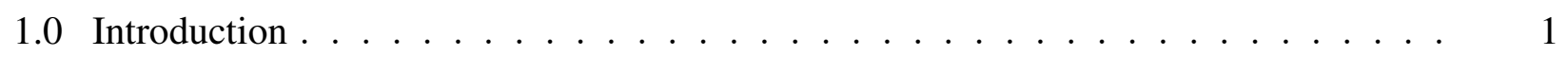

$2.0 \quad$ Axial Flow Marine Hydrokinetic Turbine $\ldots \ldots \ldots \ldots$

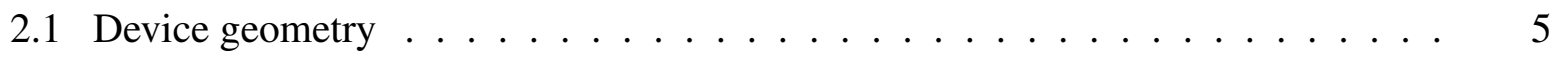

2.2 MHK Turbine performance characteristics $\ldots \ldots \ldots \ldots \ldots$

3.0 Computational Methods $\ldots \ldots \ldots \ldots \ldots$

3.1 Computational fluid dynamics (CFD) $\ldots \ldots \ldots \ldots \ldots$

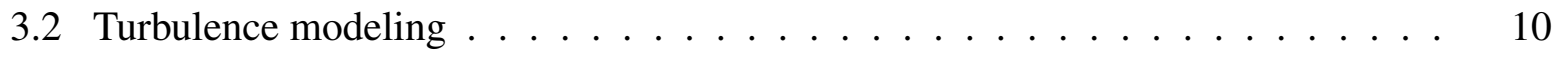

3.3 Evaluation of collision on turbine blades . . . . . . . . . . . . . . . 13

3.3 .1 Kinematic blade-strike model $\ldots \ldots \ldots \ldots 13$

$3.3 .2 \quad$ Lagrangian Particle Modeling . . . . . . . . . . . . . . . . . 14

3.4 Evaluation of Fish Survival to Blade Strike . . . . . . . . . . . . . . 17

4.0 Results and Discussion $\ldots \ldots \ldots \ldots \ldots \ldots$

4.1 Flow and turbulence fields $\ldots \ldots \ldots \ldots$. . . . . . . . . . . . . . . 21

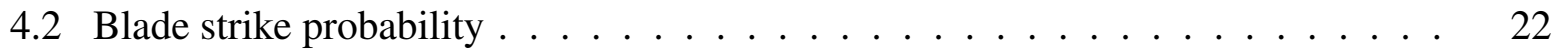

4.3 Blade strike mortality . . . . . . . . . . . . . . . . . 26

5.0 Summary and Future Work $\ldots \ldots \ldots \ldots \ldots$

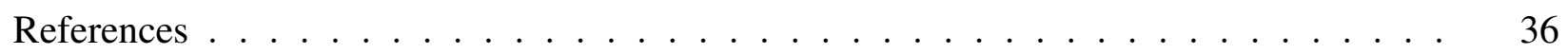

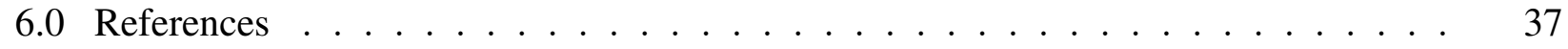




\section{Figures}

2.1 MHK turbine geometry obtained from Sandia National Laboratories. Dimensions

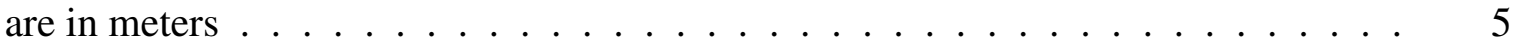

$2.2 \quad$ Power (left) and thrust (right) coefficients from BEM theory . . . . . . . . . . . . 7

3.1 Mesh and base size of cells at various refinements. $\Delta$ values are given in centimeters and $y^{+}$is dimensionless $\ldots \ldots \ldots \ldots$

3.2 Results from the two inflow turbulent conditions tested: URANS (left) and DES with SEM (right). . . . . . . . . . . . . . . . . . . . 12

$3.3 \quad$ Velocity vectors at the blade (from Dauble et al, 2007) $\ldots \ldots$. . . . . . . . 13

3.4 Side (left) and front (right) views of the array of injectors from where Lagrangian particles were released . . . . . . . . . . . . . . . 15

3.5 The assumed averages of fish length $(\mathrm{L})$ and the diameters $\left(D_{\text {part }}\right)$ of equivalentmass spheres $\ldots \ldots \ldots \ldots \ldots$

3.6 Survival rate of fish exposed to blade strike from experiments of Amaral and Hecker

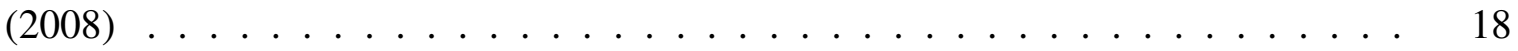

$3.7 \quad$ Blade thickness $\ldots \ldots \ldots \ldots \ldots$

$3.8 \quad$ Strike velocity of a colliding particle . . . . . . . . . . . . . . . . 20

4.1 Thrust and power from two flow simulations (URANS vs DES) at stream flow veloc-

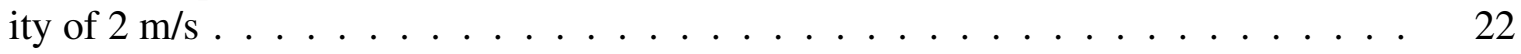

$4.2 \quad$ Iso-surfaces of Q-criterion based upon a URANS and DES turbulence modeling . . 28

$4.3 \quad$ Power (left) and thrust (right) coefficients from BEM theory and CFD simulations . 29

4.4 Particle tracks originating from the same injector and resulting from URANS (blue) and DES (red) turbulence simulations . . . . . . . . . . . . . . . 30

4.5 The change in particle location on a YZ-plane as it travels downstream . . . . . . 31

4.6 Frequency distribution of radial location (top), blade thickness (middle), and impact velocity for colliding particles of mid-size at $2 \mathrm{~m} / \mathrm{s}$ approach velocity . . . . . . . . 32

4.7 Three modes of Lagrangian particle interaction with the rotating blades . . . . . . . 33 


\subsection{Introduction}

Power production using marine hydrokinetic (MHK) energy converters is an emerging technology for renewable energy production that has recently gained worldwide interest as one component of national strategies to tap renewable energy sources. A report by Schweizer et al. (2011) documented information collected from the Federal Energy Regulatory Commission (FERC) in relation to proposed and ongoing hydrokinetic projects in the USA. Within the summary, they described the types of systems, geographical distributions, extent of the projects (single or "farm" units), the potential interactions with fish populations, etc. Commonly labeled as "underwater" power sources by early researchers (Bahaj and Myers 2003, Batten et al. 2006), the main feature of hydrokinetic turbines is the operation at zero- or near zero-head hydraulic conditions; therefore, the device acts to transform the kinetic energy of flowing water into driving energy to activate an electric generator (Lago et al. 2010, Mukherji et al.2011). Hydrokinetic technology falls into two primary categories: those units that use river flow energy and those that extract energy from tidal currents in estuaries and coastal oceans (Lago et al.2010). The present study focuses on the latter type, also known as marine hydrokinetic (MHK) or tidal current energy converter (CEC) turbines.

Hydrokinetic turbine technology is still at an early stage of development and testing at various laboratory and on-site pilot installations. Hydrokinetic technology is promising in that it is less dependent on weather conditions compared to other renewables such as wind or solar. It is also possible that MHK devices may have less impact on the aquatic ecology of the installation site compared to conventional hydropower. These energy generation devices can also be installed near population centers, thus reducing transmission costs. On the other hand, apart from the understandable economic disadvantage inherent of any emerging technology, MHK turbines will inevitably interact with and alter the surrounding ecosystem, thus giving rise to potential environmental effects such as accelerating sediment transport, distorting erosion/deposition dynamics, and interacting negatively with aquatic biota by increasing the probability of hazardous strike on the blades (James et al. 2010).

The environmental impacts of hydrokinetic turbines have been addressed in various field and laboratory studies with live fish interacting with reduced-scale and prototype devices. In two associated reports, concepts from fish survival assessment in conventional hydroelectric turbines were reviewed in relation to hydrokinetic turbines in order to elucidate the potential similarities and differences between the two technologies (Amaral et al.2011a). The preliminary conclusions pointed to a lower biological impact of hydrokinetic turbines in comparison to the hydropower counterparts owing to the less-abrupt changes in flow direction, slower passing velocities, lower pressure differential, and the absence of engineered structures with collision potential for fish, such as the wicket gates and stay vanes. The follow-up report determined injury and survival rates, as well as behavioral effects of live fish encountering hydrokinetic turbines (Amaral et al.2011b). The experimental design consisted of two types of turbines (spherical, cross-flow and axial-flow), two flow conditions, two fish species, and two size groups. The document also reports on the application of a classic kinematic model to evaluate bladestrike probabilities, a method that was also revisited and applied in the present study. Gorlov (2010) described a tidal power project on the U.S. East Coast of a proposed helical turbine design and its potential consequences on fish passage safety. The study points to a very limited prob- 
ability of fish mortality owing to the "sufficient open space for fish passage". Another study (Normandeau Associates 2009) characterized field-based rates of survival, injury and predation of living fish through an operating on-site hydrokinetic turbine (HGE hydrokinetic system, Hydro Green Energy, Houston, TX) with three blades, low rotation rate and $3.66 \mathrm{~m}$-rotor diameter. The turbine was located at the tailrace of the Mississippi Lock and Dam No. 2 near Hastings, Minnesota. Two fish size groups were released (sample ranges of $115-235 \mathrm{~mm}$ and $388-710 \mathrm{~mm}$ ) at operating conditions that gave rise to stream flow velocities ranging from 1.73 to $2.95 \mathrm{~m} / \mathrm{s}$. A high survival rate (>99\%) was recorded, as well as no visible blade-strike injury or predation.

In the foregoing summary we can observe that those studies sought to directly link the operating device with living organisms. An alternative to such an approach entails a first step in which the turbine flow environment is characterized, and then, its potential biological impacts are evaluated based on known responses to the hydraulic environment created by the turbine. The objective of the present study is to describe a method for quantitative assessment of potential blade strike of fish on an MHK turbine at selected operating conditions.

The MHK technology was developed on the basis of two consolidated engineering fields: wind energy and marine propulsion. Although early reviews recognized that a rich knowledge base can be transferred from these fields (Batten et al.2006), research specialized in hydrodynamics and environmental impact of MHK turbines remains limited (Kang et al.2012). Previous computational fluid dynamics (CFD) studies described the altered flow conditions that arise in the proximity to MHK turbines by modeling the device as a sink/source term of momentum and turbulence (James et al. 2010, Churchfield et al. 2013, Harrison et al. 2010). Such an approach is advantageous in that, while being computationally affordable, it allows for the description of flow conditions over large domains, as well as for assessment of optimized placement/arrangement of multiple units "MHK turbine farms"); however, it precludes the evaluation of the most extreme and adverse hydrodynamic conditions present very close to the unit (one-turbine diameter). Instead, more recent studies have addressed the flow description near the turbine by resolving the details of the flow physics (Mukherji et al.2011, Kang et al.2012). Whereas the latter research approach (machine-scale resolution) is more computationally demanding than the former, it allows us to examine, in detail, critical knowledge gaps such as sediment transport dynamics, aquatic biota interaction, and hazards to fish passage.

The present work uses a device-scale, CFD approach and conducts the biological assessment of blade-strike probabilities using Lagrangian particle modeling. With the model-based information on collision occurrence, frequency and intensity, we ultimately estimate the survival rate of fish crossing moving MHK turbine blades.

The specific objectives are the following:

- Simulate and describe the flow characteristics and turbulence environment in the proximity of an MHK turbine of a prescribed geometry

- Verify the simulation results against expected power and thrust force performance at various operation conditions

- Evaluate the likelihood that fish will strike the rotating blade during passage through the 
turbine

- Assess the survival rate of fish colliding with the operating turbine blades based on the intensity of the strike event

The report is organized in the following manner. We begin by presenting the prescribed geometry of the device used in the study, as well as the expected power and thrust performance derived from the blade element method (BEM) calculations. In the next section, we describe the CFD approach that was conducted in order to achieve a detailed characterization of the flow and turbulence environment near the turbine. This includes a description of the domain descritization techniques and flow solvers. This section also highlights the two additional features that we implemented in order to quantify the probability of blade-strike: the generation of inflow turbulence and the modeling of fish bodies as Lagrangian particles. The discussion of results highlights the improved features of the present approach over the older, conventional blade strike modeling methods. Finally, we offer suggestions for future work in this area of research. 



\subsection{Axial Flow Marine Hydrokinetic Turbine}

\subsection{Device geometry}

The marine hydrokinetic turbine evaluated in the present study was designed based upon experience with wind turbine airfoil analysis and considerations of hydrodynamic conditions (Shiu et al. 2012). In the design process, the following objectives were pursued: (i) maximizing hydraulic performance with respect to lift/drag ratio, (ii) minimizing sensitivity to soiling to economize on maintenance cost, (iii) providing sufficient thickness for bending stiffness, (iv) incorporating adequate stall features, and (v) minimizing cavitation and singing, the latter being a hydroacoustic/hydroelastic phenomenon of the trailing edges specific to operation in water environments. The hydrofoil profiles were determined with the support of the software XFOIL that contains routines for parameterizing geometries and flow condition distributions. The general dimensions of the MHK device are shown in Figure 2.1

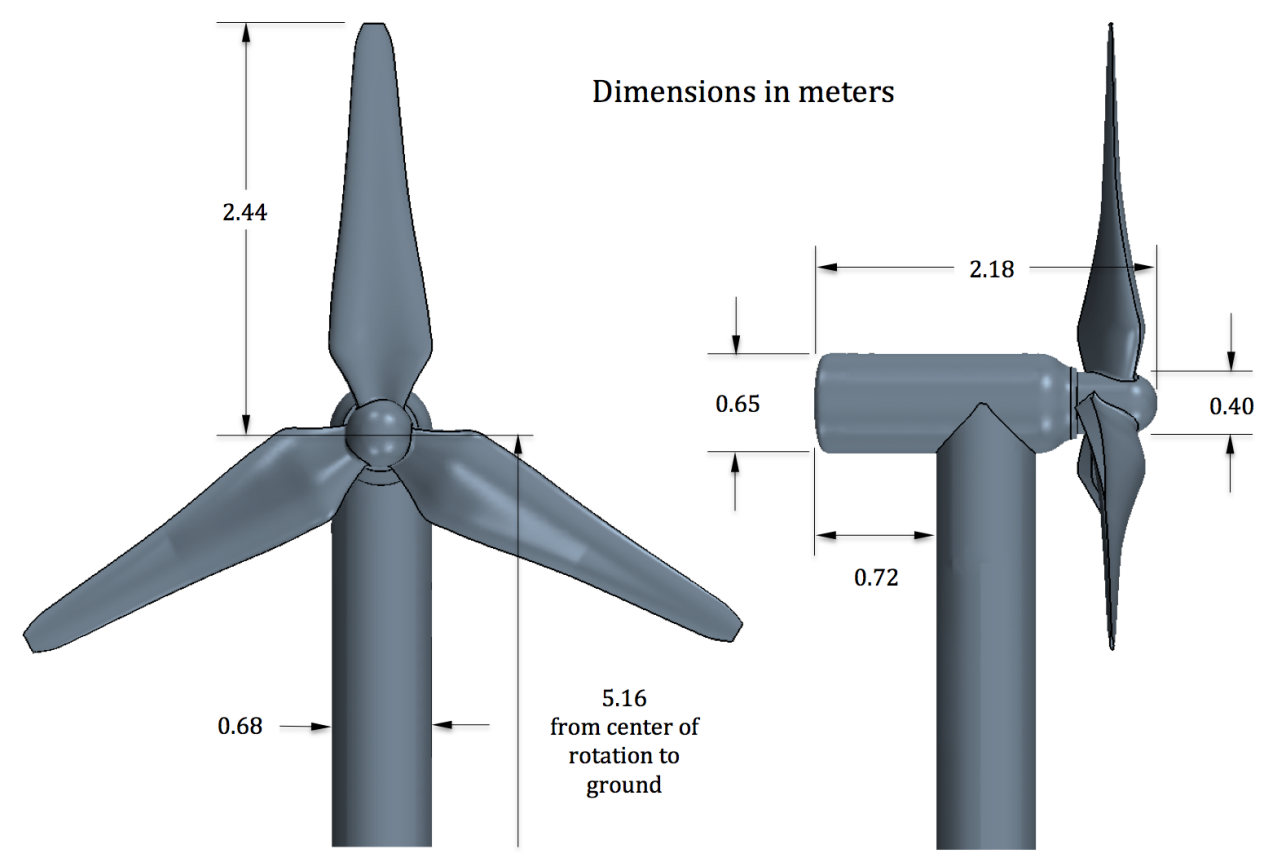

Figure 2.1. MHK turbine geometry obtained from Sandia National Laboratories. Dimensions are in meters

\subsection{MHK Turbine performance characteristics}

The blade element method (BEM) was used by Sandia National Laboratories to design the blade shape of the MHK unit in the study. The design optimization consisted of maximizing the percentage of power to be extracted from the free stream $\left(C_{P}\right)$ while minimizing the axial momentum imparted by the flow stream onto the device surface $\left(C_{T}\right)$. In order to quantify the 
performance, the power coefficient $\left(C_{P}\right)$ is defined in the following relationship:

$$
C_{P}=\frac{P_{O U T}}{\frac{1}{2} \rho U^{3} A}
$$

Where $P_{O U T}$ is the output power of the device $(\mathrm{W}), \rho$ is density of water $\left(\mathrm{kg} / \mathrm{m}^{3}\right)$, U is the freestream reference velocity $(\mathrm{m} / \mathrm{s})$ and $A$ is the turbine swept area $\left(\mathrm{m}^{2}\right)$. Additionally, the thrust coefficient is calculated as:

$$
C_{T}=\frac{T}{\frac{1}{2} \rho U^{2} A}
$$

Where $\mathrm{T}$ is the thrust force $(\mathrm{N})$. The turbine tip speed ratio (TSR) relates the tip tangential velocity (at maximum radius $\mathrm{R}$, in $\mathrm{m}$ ) to the free-stream reference velocity, where $\omega$ is the rotating speed $(\mathrm{rad} / \mathrm{s})$ :

$$
T S R=\frac{R \omega}{U}
$$

The BEM approach was carried over from wind turbine design methods and has historically been a common modeling approach for blade design of wind energy systems (Batten et al. 2006). Briefly, BEM theory consists of equating the flow momentum and surface forces (friction and pressure) to define the performance of a section (lifting foil) of known characteristics from radius (r) to radius $(r+\Delta r)$. Therefore, the local blade forces are later integrated over the entire blade in order to obtain the overall device performance. The technique is an adequate approximation because of the relatively high aspect ratio expected of wind and MHK turbine blades. Conventionally, a prescribed foil section (or composition of prescribed sections) provides the starting geometry for analysis.

BEM performance results are used as a baseline in order to confirm the CFD simulation outcomes since experimental validation data were not available at the time this study was performed. Figure 2.2 shows the values of power and thrust coefficients as a function of the tip speed ratio (TSR). 

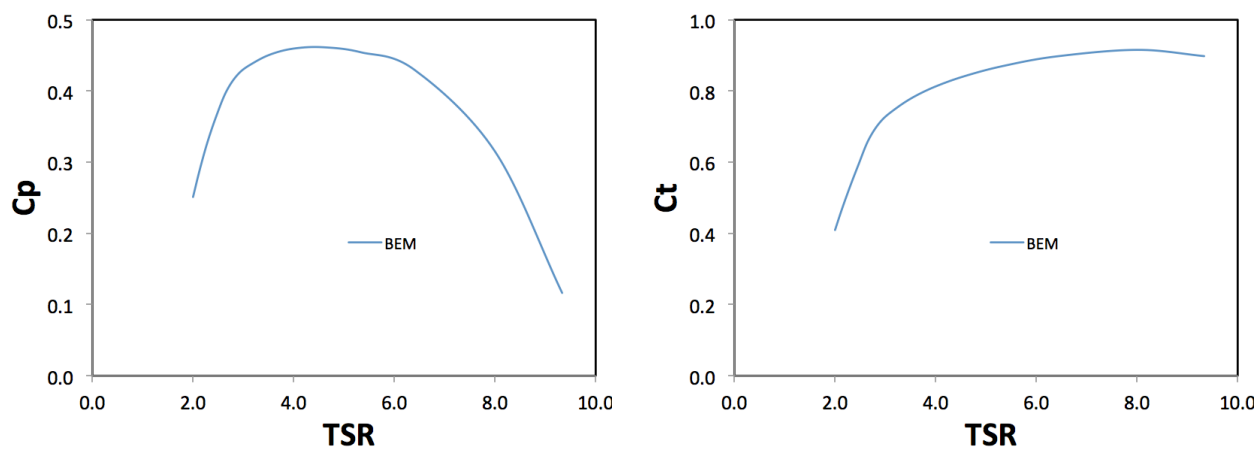

Figure 2.2. Power (left) and thrust (right) coefficients from BEM theory 



\subsection{Computational Methods}

\subsection{Computational fluid dynamics (CFD)}

Computational fluid dynamics (CFD) was used to simulate the three-dimensional unsteady flow and turbulence characteristics around the MHK device. For that purpose, the commercial software STAR-CCM+ v8 (CD-adapco 2013) was used to compute the flow and Lagrangian particle solutions. The computational domain was 80 x 40 x $20 \mathrm{~m}$ (stream-wise, span-wise, and vertical directions of the flow, respectively). The entire domain in relation to the turbine diameter (D) was approximately $32 \times 16 \times 8$, which allowed for the adequate description of the wake flow past the device as suggested by previous experience with this type of flow. The domain was discretized with a unstructured (primarily hexahedral) mesh containing approximately $10.2 \mathrm{M}$ cells. Cells were gradually refined in the proximity of the turbine unit. Figure 3.1 shows the general features of the mesh. Because finer spatial resolution was necessary near the MHK unit, approximately $30 \%$ of the cells were allocated in the rotating region containing the blade surface boundaries. The model geometry included the tower, nacelle and hub components. In order to test the mesh dependency of the flow solution, a simulation run was conducted on a refined mesh of size of $37.1 \mathrm{M}$ cells.

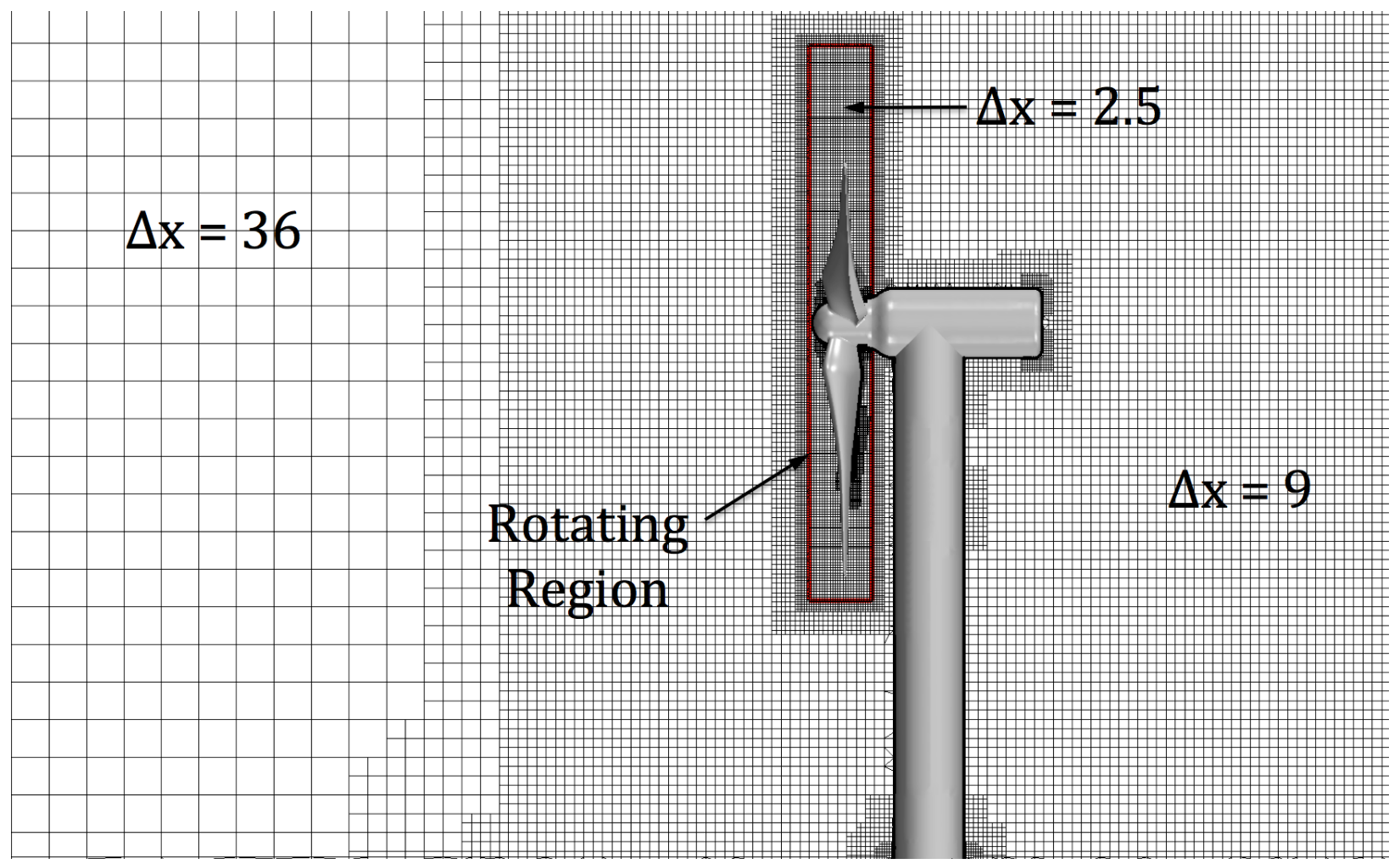

Figure 3.1. Mesh and base size of cells at various refinements. $\Delta$ values are given in centimeters and $y^{+}$is dimensionless

A segregated, isothermal flow solver was used to simulate a transient solution. The boundaries that represent the rotating blades were contained within a cylindrical region set in motion 
(see Figure 3.1) at rotating speed $(\omega)$ equal to $3.2 \mathrm{rad} / \mathrm{s}$ (30.55 RPM). The detached eddy simulation (DES) version of the $\kappa-\omega$ turbulence solver was used as means to enhance the description of the turbulent fields that developed around the MHK turbine. The DES-version of the turbulence solver poses certain extra requirements over the conventional unsteady Reynoldsaveraged Navier-Stokes (URANS) counterparts: the center of the first cell off the solid walls was kept small enough to achieve values of $\mathrm{y}^{+}<50$, the time step was set equal to $0.01 \mathrm{~s}$ ( $\Delta t^{*}$ $\left.=U_{\text {stream }} \Delta \mathrm{t} / \mathrm{D} \sim 0.004\right)$, and fluctuating inflow velocities were generated following the synthetic eddy formulation (SEM) explained in Section 3.2. There exists a tradeoff between the benefits in flow resolution by using a smaller time step and the computational time to complete a full simulation period. Additional computational overhead is incurred at each time step to map out the sliding cells that constitute the interface between the moving mesh (near the rotor) and the stationary grid. In order to minimize such computational effort without compromising the flow solution accuracy, the time step of $\Delta \mathrm{t}=0.01 \mathrm{~s}$ (rotating angle change, $\Delta \theta<2$ degrees) was selected.

In order to evaluate the performance in a range of realistic flow scenarios, three inflow velocities were simulated: 1,2 , and $3 \mathrm{~m} / \mathrm{s}$. These approximately correspond to tip speed ratios (TSR) of $8.00,4.00$ and 2.67 , respectively. The inflow velocity consisted of a constant mean profile following a power-law relationship with distance from the ground overlaid by prescribed turbulence characteristics of intensity and eddy size correspond to field measurements (Thomson et al.2012). The water surface and lateral domain boundaries were modeled as symmetry planes (reflecting flow conditions), and no flow recirculation was allowed at the outlet. The remaining boundaries (e.g., seabed, turbine tower, blades, nacelle, hub, etc.) were modeled as no-slip solid walls.

\subsection{Turbulence modeling}

Numerical simulations solve for the velocity and pressure fields at each time step. Because most environmental flows are turbulent in nature, one of the critical parts of a CFD model is selecting the way turbulence is accounted for in the flow solution, also known as the "turbulence closure problem". Typically, especially in industrial design applications, Reynolds-averaged Navier-Stokes (RANS) equations are solved using a turbulence model to integrate the effects of turbulence into the momentum equations; however, new research in turbulence simulation aims at explicitly computing turbulent flow features (velocity fluctuations) without the use of a turbulence model. The former strategy is commonly referred as unsteady RANS (URANS) while the latter is known as Direct Numerical Simulation (DNS). Whereas the DNS approach is promising and appealing, its full implementation in environmental flows demands extremely large computational resources that make it impractical at the present time. A compromise technique is the Detached Eddy Simulation (DES) approach. DES simulations model turbulence in the proximity of walls using RANS techniques ("attached" portion of the flow), whereas it resolves the turbulent eddies away from the solid boundaries "detached" flow) (Spalart 2009) using large eddy simulation (LES) methods. The DES formulation provides a computationally affordable approach for evaluating the effect of turbulence conditions on the following:

- The turbulent inflow approaching the MHK device and its wake 
- The bulk hydrodynamic performance of the MHK unit

- The particle pathways and interactions with rotating blades

Even when the CFD model is set up for higher resolution of turbulence using a DES formulation, a refined grid and a small time step, only limited improvement in the flow description is achieved if inflow turbulence is not provided. Specific to the present study, imposing only a mean inflow profile will result in no downstream fluctuations owing to the fairly uniform geometry of the model from the inlet to the MHK region, i.e., boundary induced shear will not induce the expected inflow turbulence. In these circumstances, there are normally two approaches to produce turbulent inflow conditions: a precursor simulation or the generation of synthetic turbulence. We used the latter method following the formulation proposed by Jarrin et al. (2006) called the synthetic eddy method (SEM). The SEM-based inflow was effective in that:

- It produced coherent turbulent eddies, i.e. eddies that were sustained and propagated as they traveled downstream

- It generated coherent structures based upon two turbulent characteristics that have been measured and reported in previous studies of tidal turbulence in Puget Sound, WA (Thomson et al. 2012)

- It is a well documented method and computationally affordable for implementation

The inflow turbulence was characterized by values of turbulence intensity of $11 \%$ and a Lagrangian integral time scale of $1.43 \mathrm{~s}$ (Richmond et al.2011). These turbulent conditions were experimentally quantified at a tidal current site located in Puget Sound, Washington, where future deployment of MHK devices has been proposed.

We implemented two types of inflow turbulence depending on choice of turbulence modeling. URANS simulations assumed a mean power-low velocity profile and modeling parameters for turbulence (left Figure 3.2). DES simulations included inflow eddy generation using SEM that imposed unsteady, coherent velocity fields at every time step (right Figure 3.2, three time realizations are shown). These two strategies gave rise to different turbulence environments in the computational domain (bottom figures, stream-wise velocities are normalized with respect to the mean flow velocity of $2 \mathrm{~m} / \mathrm{s}$ ). We ultimately seek to quantify the impact of such differing flow conditions on the probability that particles representing fish will collide with the rotating blades. 

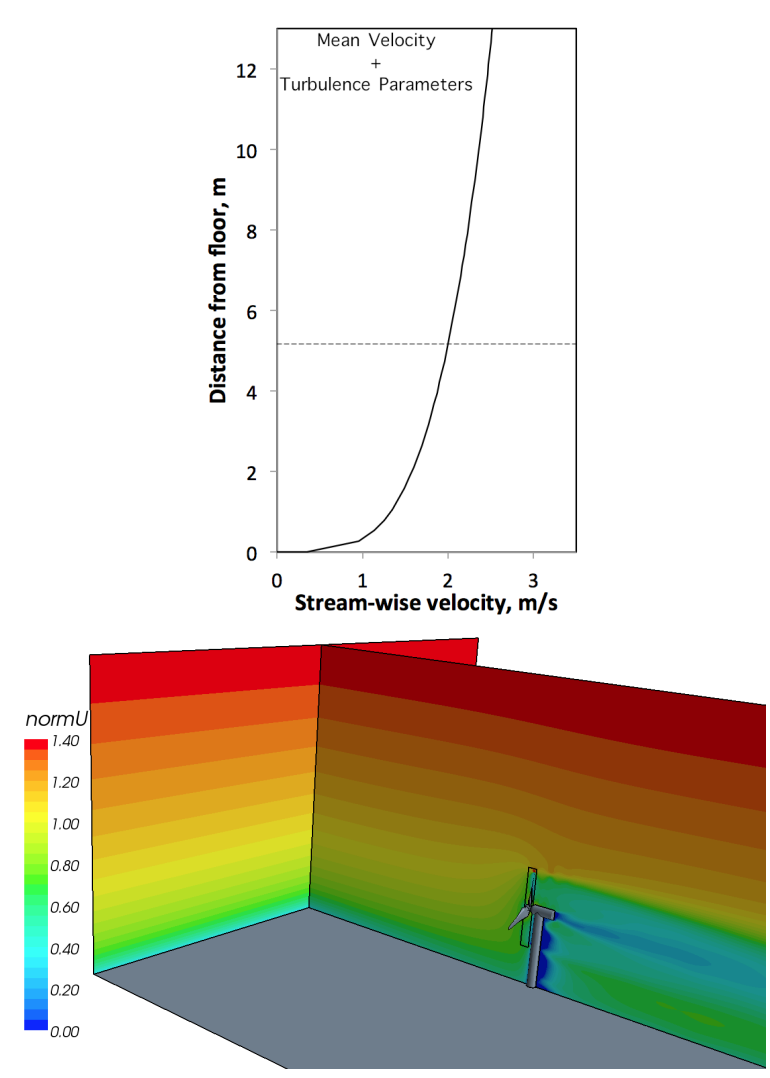

Figure 3.2. Results from the two inflow turbulent conditions tested: URANS (left) and DES with SEM (right).
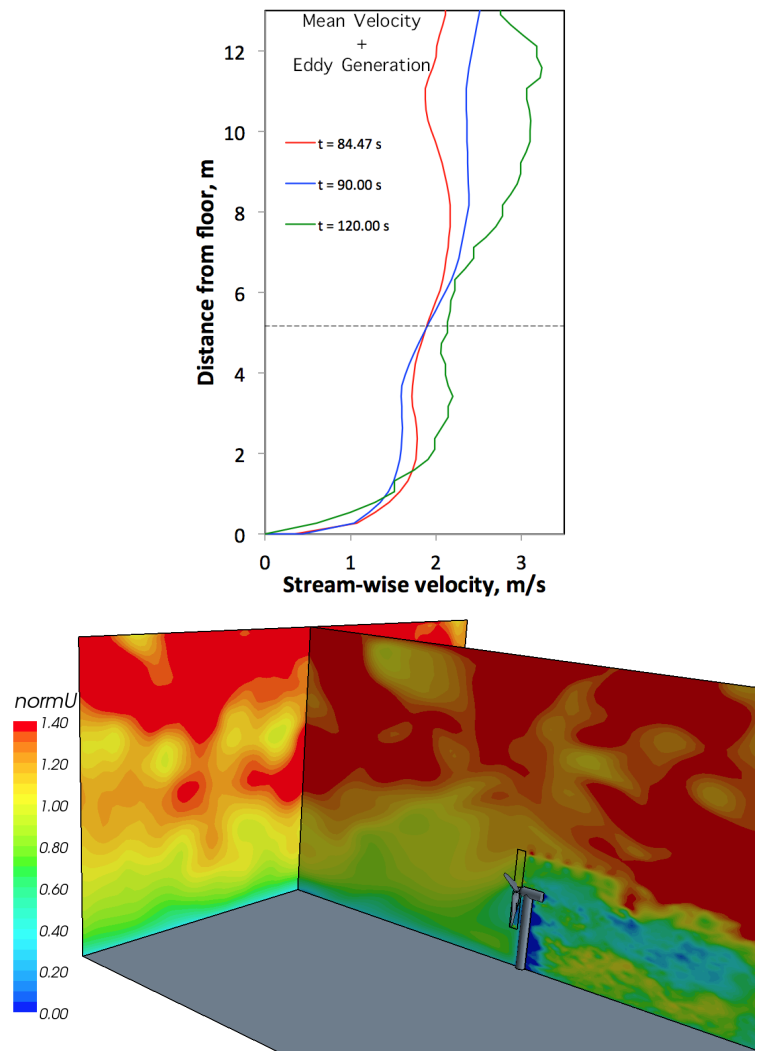


\subsection{Evaluation of collision on turbine blades}

\subsubsection{Kinematic blade-strike model}

The possibility that fish passing rotating turbine blades can be injured has long been recognized and studied. Von Raben (1957) calculated the kinematic probability of a fish impacting a rotating set of turbine blades using Equation 3.1, assuming that a fish of length $L$ approaches a turbine (of $n$ blades and rotating at $N$ rps) with a velocity $V_{\text {axial }}$ (in $\mathrm{m} / \mathrm{s}$ ) at an angle $\theta$. A sketch of the input parameters is shown in Figure 3.3 .

$$
P_{s t r}=\frac{n N L \cos (\theta)}{V_{\text {axial }}}
$$

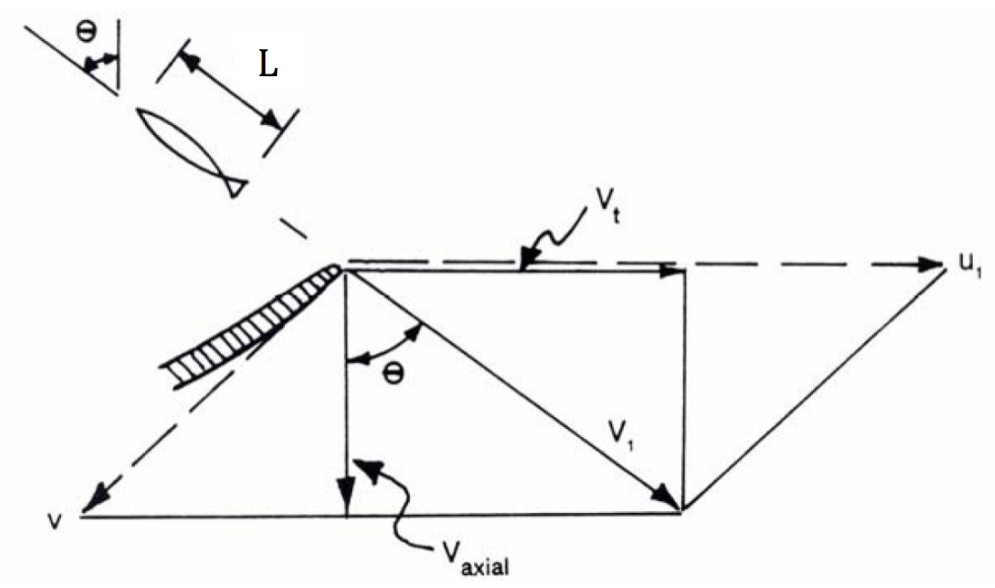

Figure 3.3. Velocity vectors at the blade (from Dauble et al, 2007). The diagram shows a fish of length (L) in flow approaching the leading edge of a runner blade in a Kaplan turbine, velocity vectors, and associated angles. $V_{t}=$ tangential velocity; $V_{1}=$ absolute velocity; $V_{\text {axial }}=$ axial velocity $; u_{1}=$ blade peripheral velocity; $\mathrm{v}=$ velocity relative to the blade; $\theta=$ the angle between axial (parallel to the runner axis) and absolute velocity vectors.

Because of the availability of good approximations for the input parameters, Equation 3.1 has been extensively applied in analyzing blade strikes occurring during fish passage through hydroelectric turbines. Given a set of geometric features and flow conditions, the main effort lies in determining the axial velocity and the approaching angle $\theta$. In the present study, we assume that $V_{\text {axial }}$ equals the stream flow velocity, for which three velocities were tested $(1,2$, and $3 \mathrm{~m} / \mathrm{s})$. In regards to the angle $\theta$, we recognized the lack of significant input data, and assumed two instances: (A) a value of $\theta=0^{\circ}$ that indicates an impact direction perpendicular to the runner plane, and (B) a uniform angle distribution over the range -90 to $90^{\circ}$, calculated $P_{s t r}$ (Equation 3.1) for each angle bin, and averaged out the $P_{s t r}$ values. Values of fish length are determined by the age composition of the species of concern established either by regulatory documents or prevalent in local conditions. In this study, we consider three sizes: 
- A small fish corresponds to migratory juvenile Salmonid species that are protected in the Columbia River system of the Pacific Northwest. The small fish is $10 \mathrm{~cm}$ long with a mass of $14 \mathrm{~g}$

- A mid-sized fish has a length of $40.6 \mathrm{~cm}$. The calculations of this length value are provided in section 3.3 .2

- A large fish corresponds to an Atlantic sturgeon of average size of $104 \mathrm{~cm}$, as reported at the Long Island Sound by Savoy (2007)

\subsubsection{Lagrangian Particle Modeling}

An alternative strategy to the kinematic blade strike probability described in section 3.3.1 is to evaluate the frequency of collision assuming that fish pathways can be represented by Lagrangian particle motion through the MHK turbine. Lagrangian particle simulation consists of tracking the trajectory of particles (with mass) through fluid flows. With this approach, we accounted for the multiple forces acting on particles that were used to represent fish. An advantage of this method is that we can simulate mechanisms of interaction between the particles (fish) and solid surfaces (turbine blades), thus aiding in the estimates of the fraction of collisions given a population of fish released upstream from the MHK device. A limitation of the method is that fish are represented as particles that simply move with the fluid and can exhibit no behavioral response such as avoidance of the MHK turbine. This limitation creates a tendency for the model to produce conservative results since it is likely that some fraction of an approaching population of fish would actively avoid the turbine. In addition, no attempt was made to approximate a non-uniform distribution of the incoming fish population that would be the case for actual site conditions.

The particle trajectories are calculated by solving the momentum balance of forces acting on a spherical particle, which include the following:

$$
\frac{d U_{\text {part }}}{d t}=F_{d}+F_{p}+F_{g}+F_{v m}
$$

where $U_{\text {part }}$ is the particle velocity, $F_{d}$ is the drag force deriving from the slip velocity between the particle and the flow, $F_{p}$ is the force owing to the presence of pressure gradients, $F_{g}$ is the gravity force and $F_{v m}$ is the "virtual mass" force. The STAR-CCM+ solver used in this study can compute particle trajectories based on these forces. The software documentation (CD-adapco 2013) provides the detailed formulation of each component in Equation 3.2.

Flow velocities were monitored at various locations in the computational domain in order to determine the time at which statistical steady-state was reached. Normally, it took from 60 to 90 seconds to reach that point, which translated into approximately 1.5 to 2 "flow-through" times depending on the inflow velocity. After that stabilization period, spherical particles were released for 15 seconds $\left(T_{i n j}\right)$ from injectors placed $10 \mathrm{~m}$ upstream from the MHK turbine in a grid-like arrangement of size $6 \mathrm{~m} \times 6 \mathrm{~m}$, centered at the axis of rotation, and at a spacing of $0.1 \mathrm{~m}$ 
$\left(N_{i n j}=60 \times 60=3600\right.$ injectors, see Figure 3.4). Each time step $(\Delta \mathrm{t}=0.01 \mathrm{~s})$, release locations were randomized within the grid, with a probability of $P_{i n j}=0.0015$, which results in a total number of injected particles $\left(N_{\text {total }}\right)$ that approximates 8100 .

$$
N_{\text {total }}=\frac{N_{i n j} * P_{i n j} * T_{i n j}}{\Delta t}=8100
$$
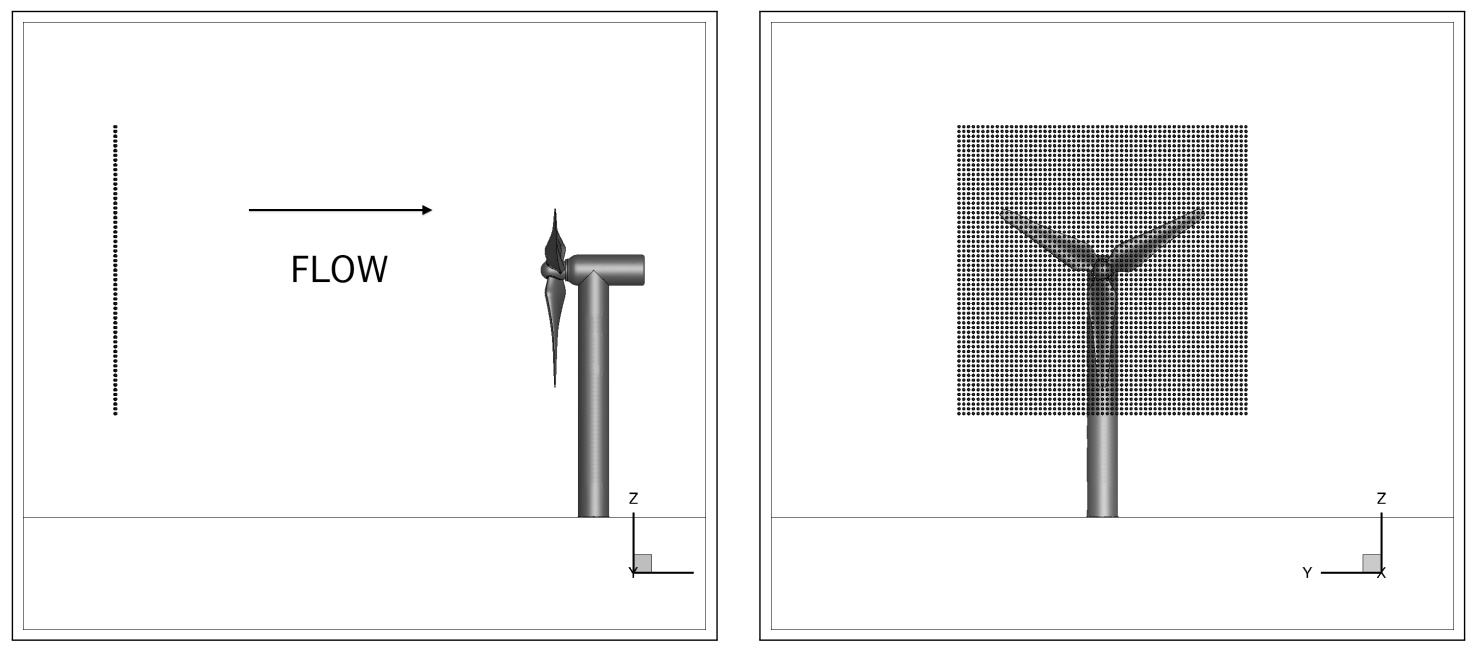

Figure 3.4. Side (left) and front (right) views of the array of injectors from where Lagrangian particles were released

Spherical particles were assumed to be neutrally buoyant (specific gravity equal to 1.0) with a diameter that results in the fish mass indicated in section 3.3.1. Based on the selection of an assumed fish length it is possible to estimate the fish mass (Figure 3.5). For the small fish, the mass is taken from assumptions made in previous studies on the passage of juvenile salmonid species through hydroelectric turbines (Dauble et al. 2007, Richmond et al. 2013a). A neutrallybuoyant sphere of mass equal to typical $100 \mathrm{~mm}$ long juvenile salmon has a diameter of 0.03 $\mathrm{m}$. For the large fish, we use the regressions of length (in $\mathrm{mm}$ ) - mass (in grams) provided by Schwartz (1997) for Atlantic sturgeon at two sites (labeled as "Corolla" and "Avon-Hatteras", equations 3.4 and 3.5). For $\mathrm{L}=1040 \mathrm{~mm}$, the equations will produce mass values of 8034 $\mathrm{g}$ and $4020 \mathrm{~g}$, respectively, the average being $6027 \mathrm{~g}$. A sphere of mass equal to the average mass value has a diameter of $0.226 \mathrm{~m}$. Finally, for a mid-size fish, we directly assume a sphere diameter that falls in between the two extremes, $\mathrm{D}=0.10 \mathrm{~m}$, for which the fish mass will be $526 \mathrm{~g}$. Fish biologists consider a generic relationship of length-weight that follows the form of Equation 3.6. Therefore, we can fit the two sizes (small and large fish) into Equation 3.6 in order to estimate a mid-size fish length of $0.406 \mathrm{~cm}$. Table 3.1 summarizes the three fish sizes, mass values and equivalent diameters of spherical particles in order to run the kinematic blade-strike model and the Lagrangian particle solver.

$$
\log (M)=-4.9461+2.9337 \log (L)
$$




$$
\log (M)=-1.7102+1.7615 \log (L)
$$

$$
M=a * L^{b}
$$

Table 3.1. Fish length, mass, and equivalent diameters of spherical Lagrangian particles

\begin{tabular}{|l|c|c|c|}
\hline Size & Length, $\mathrm{m}$ & Mass, $\mathrm{g}$ & $D_{\text {part }}, \mathrm{m}$ \\
\hline Small & 0.100 & 14 & 0.030 \\
Mid & 0.406 & 526 & 0.100 \\
Large & 1.040 & 6027 & 0.226 \\
\hline
\end{tabular}
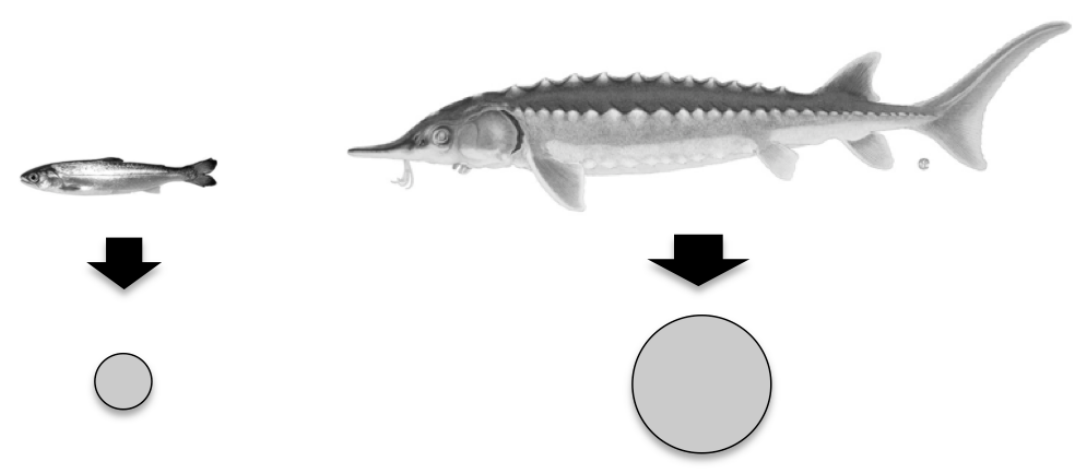

Figure 3.5. The averaged fish length $(\mathrm{L})$ and the diameter $\left(D_{\text {part }}\right)$ of an equivalent-mass sphere were used to calculate probability of strike $\left(P_{s t r}\right)$ and fraction of collisions $\left(F_{\text {imp }}\right)$, respectively, for a juvenile Salmonid species (left) and an adult Atlantic sturgeon (right)

As depicted in Figure 3.4 the grid of injectors extends beyond the MHK sweep area. In the post-processing stage, the fraction of collisions $\left(F_{\text {imp }}\right)$ was defined as the ratio of the number of hits with respect to the number of particles that have any potential for being impacted, i.e., we account for only those particles crossing the turbine sweep area at any time during its movement downstream. Because the interaction of particles with blades was set to rebounding with tangential and normal restitution coefficients equal to 1.0, only single hits are included in the fraction of collisions, i.e., if a particle hits the blade multiple times, it still counts as a single colliding particle. This refinement allowed for comparisons of the two methods in this study: the kinematic probability of strike $\left(P_{s t}\right.$, section 3.3.1) and the fraction of collisions $\left(F_{i m p}\right)$ of Lagrangian particles. 


\subsection{Evaluation of Fish Survival to Blade Strike}

Any collision on a rotating MHK turbine blade is only harmful if the collision conditions result in direct or indirect injury or mortality on the fish. The physical evidence indicates that when a direct injury does take place, it can take the form of decapitation, severing of the body, tears, descaling, and bruising (Turnpenny et al.2000). The quantitative analysis of injury mechanisms that fish experience while interacting with engineered systems has proven to be challenging owing to the numerous uncertainties that a collision event entails. Note that indirect injury refers to injuries not immediately caused by the turbine, but those occurring due to mechanisms such as disorientation by severe turbulence that could make fish vulnerable to predation from other fish or birds.

Previous studies experimentally evaluated the survival of various species of fish that crossed prototype hydrokinetic devices in conditions that are likely to be found in potential MHK deployment sites (Amaral et al. 2011b, Castro-Santos and Haro 2012). They also tested the effect of the fish body size and prototype designs on the survival rate. They found survival rates that were relatively high (always greater than 90\%) regardless of the test conditions. Although the laboratory experiments are independent of the present modeling efforts, certain underlying assumptions are similar. First, two approach flow velocities were tested. Second, the fish size was a test parameter. Last, the survival rates are based upon fish individuals that were contained within a net upstream from the device in order to eliminate the likelihood of avoidance, which turned out to be high in the preliminary runs with releases far upstream from the devices. The outcomes from these studies gave a clear indication that exposure to collisions and other injury mechanisms result in low mortality rates. However, having tested an array of a few discrete experimental conditions, the outcomes did not allow for the development of an empirical model to estimate survival rates of fish passing though hydrokinetic devices. Therefore, the present study calculates the survival rate of fish colliding on the MHK blades by following the biological performance assessment (BioPA) framework proposed by Richmond et al. (2013b a) and applied to hydroelectric turbines based on studies by Amaral and Hecker (2008). More details on the blade-strike type of injury, the underlying modeling assumptions, and the involved uncertainty are found in Richmond et al. (2013a).

In the present application we determined the probability of survival (survival rate, SR) for each collision event that was modeled by the Lagrangian solution scheme described in the previous sections. Figure 3.6 shows the experimental laboratory results from Amaral and Hecker (2008) in which SR was determined as a function of the blade thickness $(T)$, the fish length $(L)$ and the strike velocity $(\Delta \mathrm{V})$ over a variety of test conditions that allowed for the construction of an empirical relationship as in equation 3.7. A brief summary of the experimental conditions can provide the extents as well as the limitations of the experimental results in the context of the present modeling efforts. The range of fish length was $100-760 \mathrm{~mm}$, whereas the blade thickness ranged from $10 \mathrm{~mm}$ to $150 \mathrm{~mm}$. The selected combinations of these two conditions gave rise to ratios of $L / t$ varying from 0.67 to 30 . Fish of sizes ranging from 100 to $760 \mathrm{~mm}$ were held at a vertical position to expose them to the strike of a blade moving at speeds $(\Delta \mathrm{V})$ that ranged from 3.0 to $12.2 \mathrm{~m} / \mathrm{s}$. The selected fish species were rainbow trout (Oncorhynchus mykiss), white 
sturgeon (Acipenser transmontanus), and American eel (Anguilla rostrata).

$$
S R=f\left(\Delta V, \frac{L}{T}\right)
$$

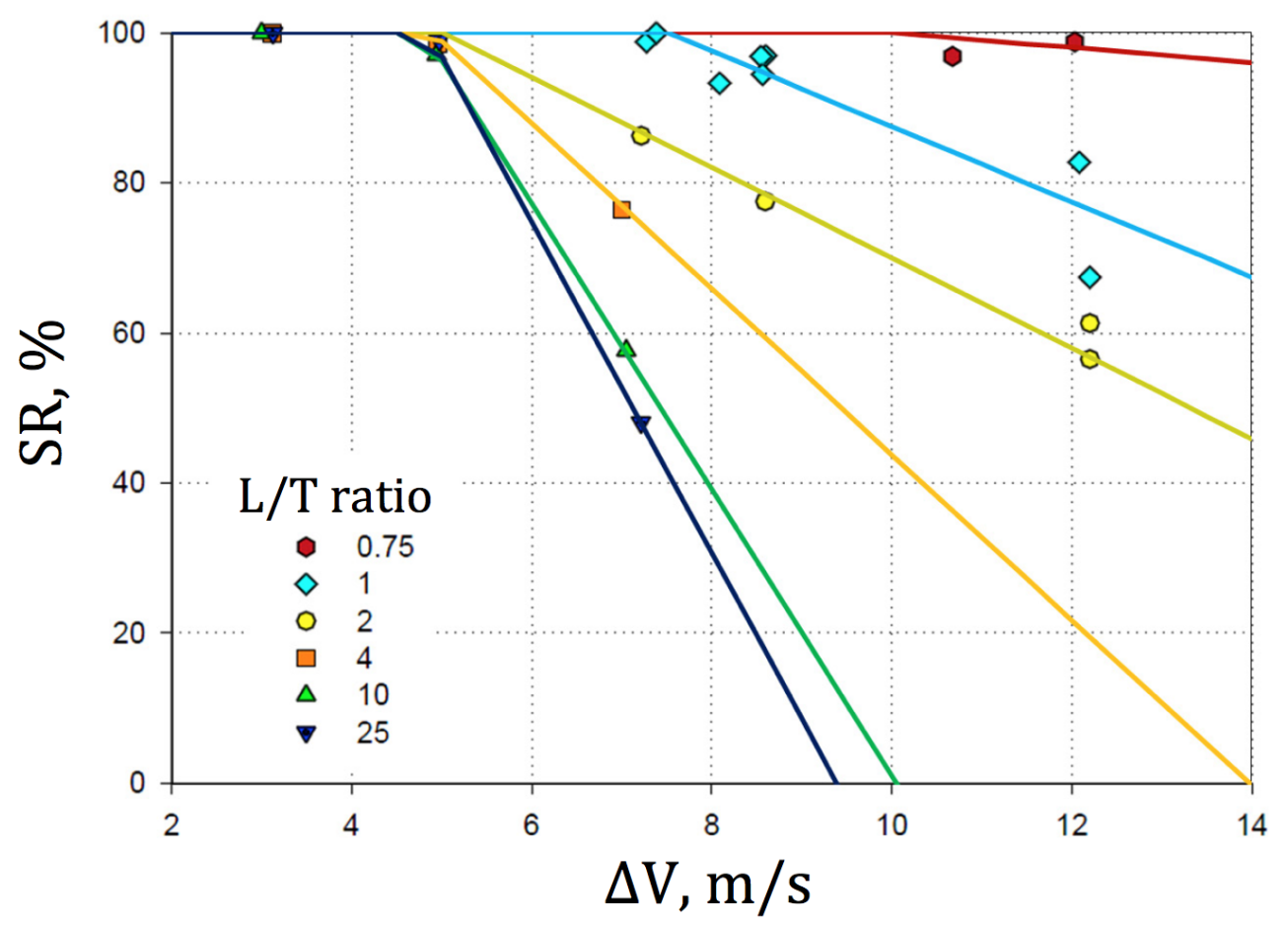

Figure 3.6. Survival rate of fish exposed to blade strike from experiments of Amaral and Hecker (2008)

The values of fish length in the present work are summarized in Table 3.1, whereas the blade thickness is estimated as twice the minimum radius of curvature of the leading edge profile. The blade thickness was calculated at various radial locations along the blade. Figure 3.7 shows an example of the blade thickness at a cross section located at $\mathrm{R}=1.4 \mathrm{~m}$, along with the curve of $\mathrm{T}$ as a function of $\mathrm{R}$. The Lagrangian solver recorded the coordinate locations $(\mathrm{x}, \mathrm{y}, \mathrm{z})$ of the strike events, from which we calculated the radial distance with respect to the center of rotation, and, ultimately, the blade thickness at the impact location.

The impact velocity, $\Delta \mathrm{V}$, (Equation 3.8), is calculated as the difference between the blade velocity $\left(V_{b}\right.$, Equation 3.9) and the tangential fish velocity $\left(V_{f}\right)$ at the moment of impact (Figure 3.8).

The three components of the particle impact velocity $(\overline{\mathrm{U}})$ of Lagrangian particles were sampled immediately before strike to determine $V_{f}$ along the unit vector, $\hat{\mathrm{t}}$, using Equation 3.10 . Lastly, the estimated survival rate for the entire particle population is the averaged SR of all particles, 

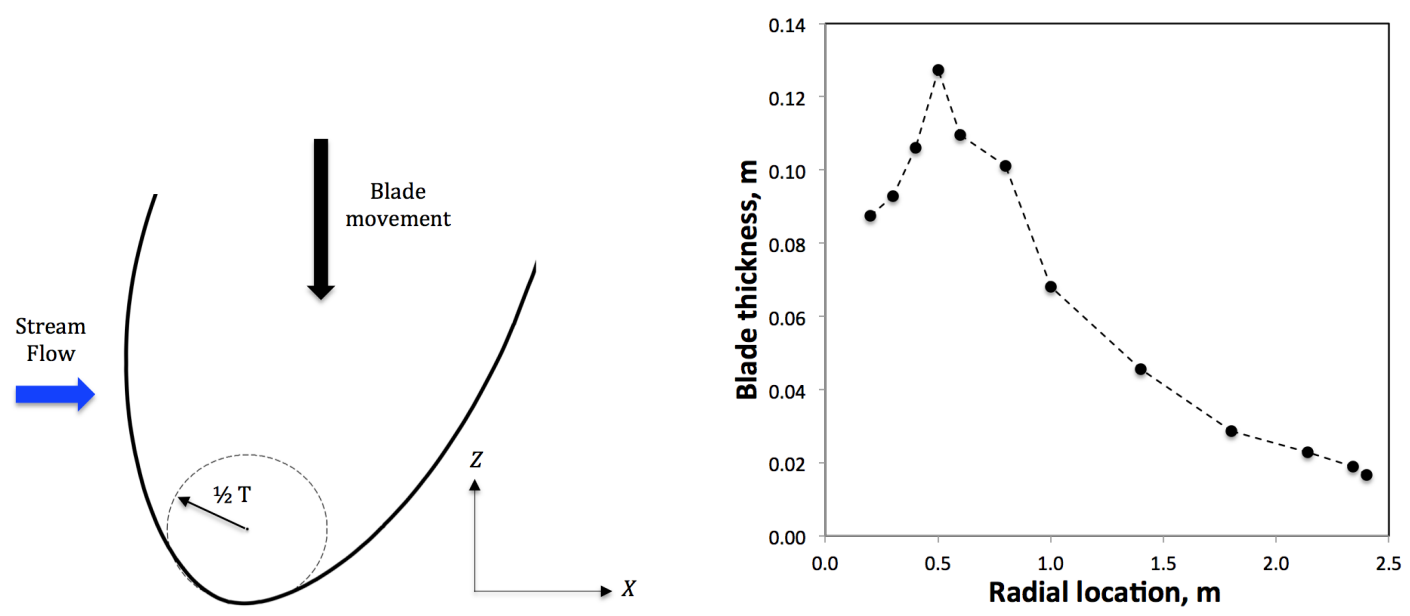

Figure 3.7. Blade thickness of cross section at $\mathrm{R}=1.0 \mathrm{~m}$ (left) and the thickness at multiple cross sections along the blade (right)

with a non-striking particle having a $\mathrm{SR}=1.0$.

$$
\begin{gathered}
\Delta V=\left|V_{b}-V_{f}\right| \\
V_{b}=R * \omega \\
V_{f}=\bar{U} \cdot \hat{t} \\
\hat{t}=\frac{1}{\sqrt{Y_{0}^{2}+Z_{0}^{2}}} *\left(Z_{0} \hat{j}-Y_{0} \hat{k}\right)
\end{gathered}
$$

We also evaluated the survival rates based on the kinematic model in section 3.3.1. In such case, the impact velocity $(\Delta \mathrm{V})$ is equal to the blade velocity $\left(V_{b}\right)$ as the fish is assumed to enter the impact plane perpendicularly, i.e., $\overline{\mathrm{U}}=\left(V_{\text {axial }}, 0,0\right)$. Because $V_{b}$ depends on the radial location, and the distribution of the fish at the impact plane is unknown, we calculated the survival rate over 10 bins equally spaced in the radial direction, and weighted them by the annular area of each bin in order to obtain a global survival rate for the MHK device $\left(S R_{\text {global }}\right)$. This value still needs to be weighted by the probability that a strike event takes place; therefore, the ultimate survival rate is defined as $S R=1-P_{\text {str }} \cdot\left(1-S R_{\text {global }}\right)$. 


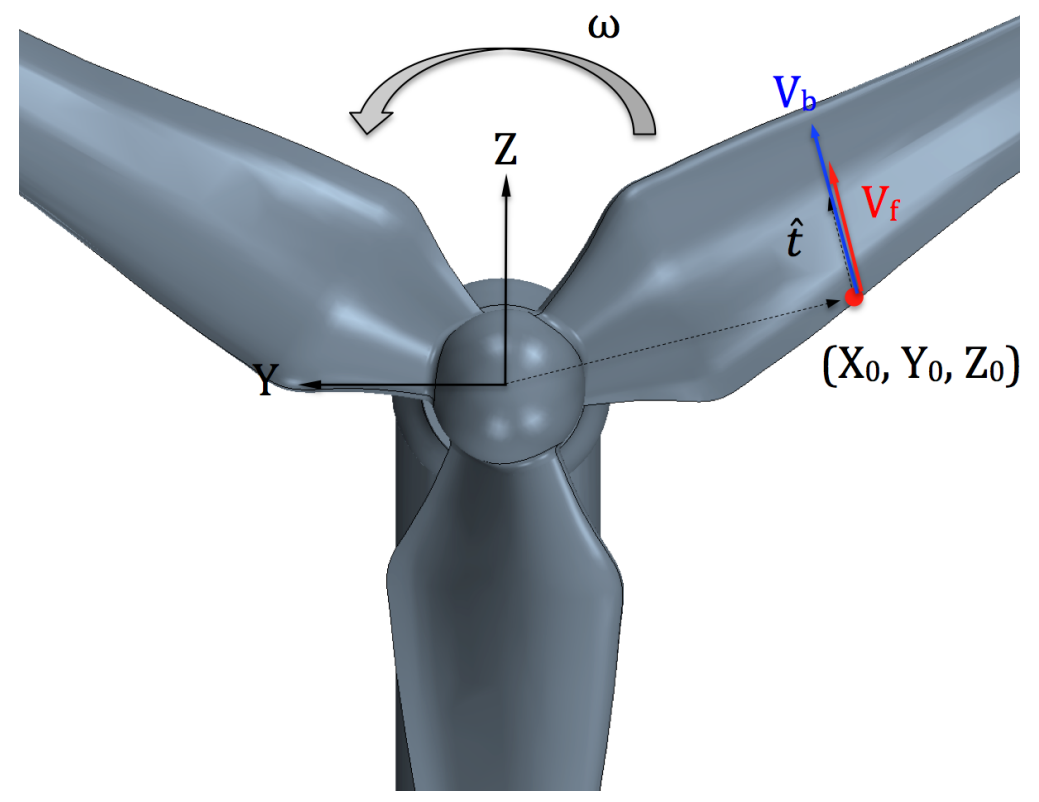

Figure 3.8. Strike velocity of a colliding particle 


\subsection{Results and Discussion}

\subsection{Flow and turbulence fields}

This section presents the main findings related to the flow simulation results followed by the analysis of the Lagrangian approach to quantify probability of collision. Figure 4.1 shows the computed output power and thrust values deriving from the case of $U_{\text {stream }}=2 \mathrm{~m} / \mathrm{s}$ when using the URANS and DES turbulence modeling approaches. The DES outcomes contain a wide range of time scales owing to the enhanced description of turbulent structures initially imposed on the inlet boundary. Visibly, the time history of output power consists of two, apparently random signal frequencies. The large scale oscillations are driven by the large scale eddies traveling through the MHK turbine; superimposed is the periodicity owing to the effect of the rotating blades passing through the tower shadow/wake. The time record of thrust is highly correlated to that of the power as shown by the time scales composing the signal. The power output ranged from 16.8 to $47.0 \mathrm{~kW}$ (range $=30.2 \mathrm{~kW}$ ) with an average of $33.4 \mathrm{~kW}$, whereas the thrust force oscillated from 19.9 to $35.5 \mathrm{kN}$ (range $=15.6 \mathrm{kN}$ ) around an average of $28.8 \mathrm{kN}$.

A different pattern is observed for the URANS results in which a single frequency-mostly driven by the turbine rotation-is clearly observed. In terms of the mean quantities, the URANS averages of power and thrust $(31.9 \mathrm{~kW}$ and $29.2 \mathrm{kN}$, respectively) are only slightly different with respect to the DES counterparts ( $-4.5 \%$ and $1.4 \%$, respectively). However, the variability, expressed in terms of the range, is significantly lower $(3.1 \mathrm{~kW}$ and $1.9 \mathrm{kN})$. In general, we see that the averaged quantities are captured by both turbulence solvers, whereas the variability of the flow environment is explicitly computed only by advanced turbulence modeling approaches, such as the DES with inflow turbulence generation. These differences can have an effect on dynamic loads on the turbine blades. In following sections, we will further examine the effect of the enhanced description of turbulence in relation to the transport of Lagrangian particles to simulate fish particle pathways.

Figure 4.2 shows iso-surfaces of Q-criterion as a means to depict the differing flow environments that arose from the presence of the rotating turbine, for the two turbulence solvers at an instantaneous time step. Briefly, the Q-criterion was originally defined by Hunt et al. (1988) as a mathematical quantity to visualize coherent turbulent structures simulated with CFD tools. In both instances, the iso-surface of Q-criterion indicates two turbulent structures: spiral-like vortices generated by the rotating blade tips and less dominant structures originating over the trailing edge of the blades. Both types are relevant in the context of the extreme conditions that fish can potentially encounter if interacting with the MHK turbine. The turbulence solution modes clearly give rise to differing near-wake flows. In the DES solution, the large vortex rope extends "with three turns" behind the turbine before the structures break down and dissipate into the less altered, ambient flow surrounding the device. On the other hand, the URANS solution indicates an almost immediate mixing between the near-wake and ambient flows, judging by the shorter vortex ropes. It will be later shown how the stronger dissipation in the URANS model results in straight pathways across the turbine, and ultimately, affects the likelihood of particles colliding the blades.

In order to judge the predictive capabilities of the CFD approach, we compare the computed 


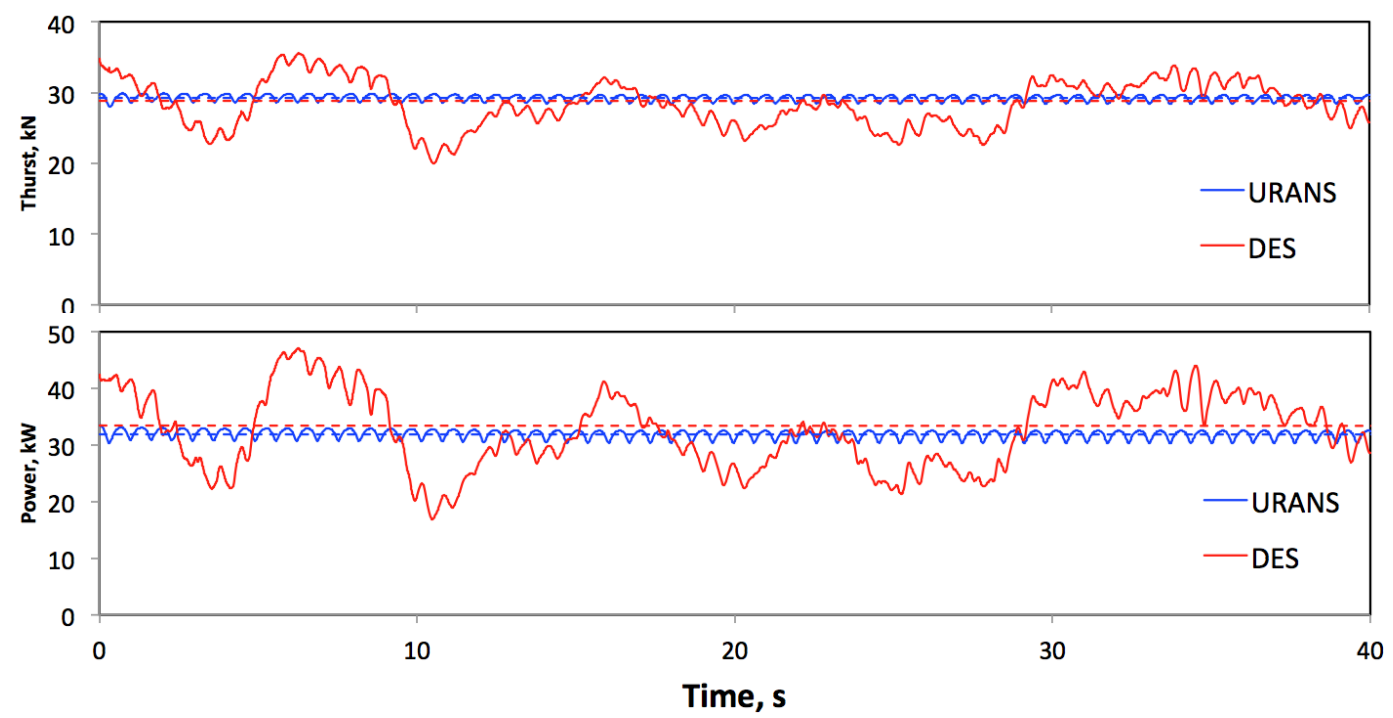

Figure 4.1. Thrust and power from two flow simulations (URANS vs DES) at stream flow velocity of $2 \mathrm{~m} / \mathrm{s}$. The dashed lines represent the average values for the corresponding colored curve

power and thrust coefficients against the corresponding BEM outcomes provide by Sandia National Laboratories (Figure 4.3). The results are in good agreement and the differences are mainly due to the underlying assumptions of both methodologies. The performance coefficients are very sensitive to the reference velocity as indicated in equations 2.1 and 2.2. Those values are prescribed in the BEM approach, whereas they are computed from the oncoming transient velocities in the CFD simulations, for which they turn out slightly different from the nominal stream flow velocities. Additionally, the CFD model is complete in that it includes the accessory parts (nacelle, hub, tower), whereas the BEM approach does not incorporate them into the analysis. Lastly, and specific to the DES solution, Figure 4.1 shows that the simulation time has allowed for only few cycles of the large timescale oscillations; therefore, further extension of the simulation time will likely develop statistically steady power and thrust coefficient values. Table 4.1 summarizes the power and thrust coefficient values. Additionally, the difference in hydraulic performance as obtained from a refined mesh $(37.1 \mathrm{M}$ cells) is small; therefore, the succeeding calculations of blade strike are conducted on the coarser mesh for calculation efficiency (size equal to $10.2 \mathrm{M}$ cells).

\subsection{Blade strike probability}

The Lagrangian particles tracks are sensitive to the turbulence modeling approach. Figure 4.4 shows the tracks of two spherical particles of similar features (mid-size) when they are subject to two turbulent environments (URANS vs DES). On each frame, the spheres are released from the same injector. The distinct tracks clearly illustrate the strong influence of the resolved turbulent flow, as particle pathways on a DES simulation tend to deflect more during their travels downstream in comparison to the straight tracks arising from the URANS solution. In order to provide a quantitative description of the displacement, we define the rate of change in radial location $\left(U_{R}=\frac{d R}{d t}\right)$ with respect to the release coordinates $\left(Y_{0}, Z_{0}\right)$, thus $\mathrm{R}=\left(\left(Y-Y_{0}\right)^{2}+\left(Z-Z_{0}\right)^{2}\right)^{0.5}$. 
Table 4.1. Power and thrust coefficient from the CFD flow simulation cases

\begin{tabular}{|l|c|c|c|c|}
\hline & & \multicolumn{4}{|c|}{$C_{P}$} \\
\hline$U_{\text {stream }}, \mathrm{m} / \mathrm{s}$ & TSR & DES & URANS & URANS-Fine \\
\hline 1 & 8.00 & 0.240 & - & - \\
2 & 4.00 & 0.461 & 0.452 & 0.460 \\
3 & 2.67 & 0.390 & - & - \\
\hline & & \multicolumn{4}{|c|}{$C_{T}$} \\
\hline 1 & 8.00 & 0.947 & - & - \\
2 & 4.00 & 0.787 & 0.812 & 0.812 \\
3 & 2.67 & 0.651 & - & - \\
\hline
\end{tabular}

The plots of $U_{R}$ with respect to the X-particle coordinate (Figure 4.5) show a pattern that repeats on most particle tracks: rapid changes occur throughout most of the particle travel downstream in the eddy-resolving scheme whereas the changes take place smoothly only near the MHK turbine in the eddy-modeled flow. Furthermore, the effect of the developed turbulent structures in the near wake flow region can also be seen in Figure 4.5.

Previous studies have shown the superior performance of eddy-resolving flow solutions to predict deposition of particles modeled as Lagrangian spheres, although the specific problem was contaminant transport within airplane cabin ventilation systems (Wang et al.|2012). In another study related to Lagrangian particle tracking supported by eddy-resolving flow simulations (Escauriaza and Sotiropoulos 2011), spheres showed intermittent, sudden, rapid motion rather than smooth displacements. The latter study is particularly of interest because it describes environmental flows altered by the presence of engineered systems, which makes it relevant to our case. Thus, we argue that the integration of advanced turbulence modeling techniques can better support further quantitative studies of MHK turbine interaction with aquatic biota and of altered sediment transport dynamics. 
Spherical particles_-and potentially, fish — interact with the rotating turbine in one of three ways: collision, rotor crossing, and complete avoidance (Figure 4.7). These modes are relevant for the assessment of probability of blade-strike, although others can occur, e.g., entrainment in turbulent wake flow or multiple collisions. The interaction depends on the location of release, on localized entrainment in a traveling eddy, and on the angular position of blades with respect to particle location at the moment of crossing. Particles impacting the blades will have a severe change in trajectory and experience acceleration/deceleration events (top frame in Figure 4.7). Those that safely cross the region influenced by the turbine experience a pathway deflection stronger than those that avoid the turbine altogether (middle and bottom frames in Figure 4.7, respectively). Rather than analyzing the interaction per particle, the present study released a sample of spheres in a random manner in terms of the injection timing and location, as described in the method (section 3.3.2). In this fashion, we obtain a global assessment of the MHK turbine from an environmental standpoint.

To test the influence of the turbulence modeling approach, Table 4.2 summarizes the fraction of collisions for the case of $U_{\text {stream }}=2 \mathrm{~m} / \mathrm{s}$, when small, mid-size and large spheres are released. Two trends are observed: (a) increasing collisions with increasing size and (b) increasing collisions with enhanced turbulence description. For the former, we hypothesize that a larger sphere takes longer time to cross the blade gaps, thus allowing for more chance of collision as in the form of Equation 3.1. This likelihood is mostly kinematic, i.e. it has to do purely with velocity and geometric features. The other part of the argument lies in the fact that smaller spheres have smaller inertia and are able to respond faster to the rapidly-changing flow conditions near the MHK blades (thus, avoiding them), in comparison to large spheres (recall that mass difference is 430X between small and large particles). For the latter trend in Table 4.2, we break up the calculation of $F_{i m p}$ values for the explanation. A fraction of all the released particles turns out not to have any potential for impact, and such fraction is influenced by the turbulence solver. DES simulations resulted in percentages of $44.7 \%, 43.8 \%$ and $35.6 \%$, whereas URANS techniques produced nearly constant values of $48.0 \%$ for small, mid-size and large spheres, respectively. Despite the larger number of particles with potential of collision, URANS values of $F_{\text {imp }}$ are indeed lower. Therefore, we hypothesize that the combination of Lagrangian solution and DES technique redistributes the particle locations towards the hub, thus increasing the fraction of collisions because of the thicker blade features toward the center of rotation. However, this argument must be tested by quantifying dispersion and redistribution of particles as they travel through the MHK device.

Table 4.2. Percentage of particles with potential of collision and fraction of collisions $\left(F_{\text {imp }}\right)$ from two flow simulation cases, URANS and DES, at $U_{\text {stream }}=2 \mathrm{~m} / \mathrm{s}$

\begin{tabular}{|l|c|c|c|}
\hline Flow case & Small & Mid & Large \\
\hline & \multicolumn{3}{|c|}{ Collision potential } \\
\hline URANS & 48.0 & 48.0 & 48.0 \\
DES & 44.7 & 43.8 & 35.6 \\
\hline & \multicolumn{3}{|c|}{ Fractions, $F_{\text {imp }}$} \\
\hline URANS & 8.3 & 9.1 & 9.5 \\
DES & 8.3 & 10.4 & 13.0 \\
\hline
\end{tabular}


Spheres and fish of different sizes tend to lower the likelihood of collision with increasing flow rate, as summarized in Table 4.3. In the case of the $P_{s t r}$ values, the lower probability results from the shorter time needed to cross the blade plane at higher velocities; in fact, the $P_{s t}$ values are linearly proportional to $U_{\text {stream }}$ for small and mid-size fish, and not so for large fish only because the values are capped at $100 \%$. The linear proportionality also holds true across the fish length values. In the probabilistic model, fish arriving perpendicular to the impact plane $\left(P_{s t r}, A\right)$ have an overall greater likelihood of strike compared to the case with uniform distribution of impact angle $\left(P_{s t r}, B\right)$. In both cases, the order of magnitude of $P_{s t r}$ is similar to those values from Amaral et al. (2011b). Lagrangian particle collisions, on the other hand, are overall lower than probabilities of strike, except for small spheres. The values of $F_{i m p}$, which were determined with Lagrangian particles, scaled up with neither the stream velocity nor with the sphere diameter. In general and compared to large particles, small and mid-size spheres are $33 \%$ and $15 \%$ less likely to collide, in all cases.

Table 4.3. Kinematic probability of strike and fraction of Lagrangian collisions from the flow simulation cases

\begin{tabular}{|l|c|c|c|c|}
\hline & & \multicolumn{3}{|c|}{ Kinematic probabilities, $P_{\text {str }}, \mathrm{A}$} \\
\hline$U_{\text {stream }}$ & TSR & Small & Mid & Large \\
\hline 1 & 8.00 & 15.3 & 62.0 & 100.0 \\
2 & 4.00 & 7.6 & 31.0 & 79.5 \\
3 & 2.67 & 5.1 & 20.7 & 53.0 \\
\hline & & Kinematic probabilities, $P_{\text {str }}, \mathrm{B}$ \\
\hline$U_{\text {stream }}$ & TSR & Small & Mid & Large \\
\hline 1 & 8.00 & 9.7 & 39.5 & 79.3 \\
2 & 4.00 & 4.9 & 19.8 & 50.6 \\
3 & 2.67 & 3.2 & 13.2 & 33.8 \\
\hline & & Lagrangian fractions, $F_{\text {imp }}$ \\
\hline 1 & 8.00 & 13.4 & 15.1 & 19.1 \\
2 & 4.00 & 8.3 & 10.4 & 13.0 \\
3 & 2.67 & 6.5 & 7.1 & 9.5 \\
\hline
\end{tabular}

Apart from tracking particle locations, the present method has the ability to track the magnitude of various flow quantities of interest for post-processing analysis, e.g. pressure, velocity components, strain rate, etc. By sampling the entire flow domain and by analyzing the trends of such variables, we can evaluate the biological performance of the MHK turbine in view of an array of potential biological stressors. In this way, we can provide comparative scores that point to turbine designs that perform better from an environmental standpoint. This approach is implemented into a software tool developed and tested at PNNL for hydroelectric turbines (Richmond et al.2013b). Particularly important is to account not only for the likelihood and frequency of collisions, but also for the intensity of such collisions, as well as for the ultimate possibility of injury or mortality. 


\subsection{Blade strike mortality}

The evaluation of blade strike mortality reveals the limitations of the kinematic method (in section 3.3.1) that ignores the individual information of impact intensity at specific locations on the blade. The proposed method by Lagrangian particle tracking, on the other hand, provided the collision data that can be used as the input data for quantitative fish mortality assessment. Table 4.4 shows the survival rate for the three particle sizes at three different approach velocities based on both the kinematic model and Lagrangian-particle simulations. The kinematic modelbased survival rates are calculated for the two crossing scenarios: fish crossing perpendicularly to the plane of the leading edge of the turbine blades, and fish crossing with a body orientation angle following a uniform distribution $\left(P_{s t r}, A\right.$ and $P_{s t r}, B$ in table 4.3). The values of SR are considerably low for large-sized fish mainly because we are accounting for the actual fish length. However, the values tend to be similar for the case of small fish regardless of the calculation method. On the other hand, the CFD-based survival rates remain relatively high, conforming to the experimental evidence that fish passage through hydrokinetic turbines have high survival rate (Amaral et al.2011b, Castro-Santos and Haro 2012, Normandeau Associates 2009). Although the survival rate decreases with fish size, the mortality is similar to that occurring in conventional hydroturbines. Figure 4.6 shows the frequency distribution of the three input parameters needed for quantitative assessment of blade strike mortality at approach velocity equal to $2 \mathrm{~m} / \mathrm{s}$. The mean values roughly correspond to a collision that occurs at the middle of the blade length with an impact velocity approximately equal to the rotating blade velocity $\left(V_{b}\right)$, indicating a small global effect of the fish velocity tangential to the runner plane, i.e., $V_{f}$ tends to be small.

The modeled values of impact velocity (chart of $\Delta \mathrm{V}$ distribution in figure 4.6) for the most part fit the laboratory conditions from which the survival rate chart (figure 3.6) was estimated (3.0 to $12.2 \mathrm{~m} / \mathrm{s})$; similarly, the blade thickness fits entirely over the test range $(10-150 \mathrm{~mm})$. The laboratory species also contemplated one salmonid-type and one sturgeon-type of fish species. Only the modeled "large" fish length $(\mathrm{L}=1.04 \mathrm{~m})$ has to be extrapolated from the experimental values (L ranged from $0.10-0.76 \mathrm{~m}$ ).

It should be noted that the driving factor for the high survival rates is the relatively low impact velocities on rotating blades of the MHK turbine. In comparison to conventional hydroelectric turbines, the present turbine design does not have a water passageway that produces contraction and acceleration of the fluid flowing through the turbine. This results in particles (and fish) velocities that are not largely different from the ambient flow velocity as they cross the rotor plane, and in turn, lower impact velocities. Additionally, the majority of planned and pilot MHK installations do not include structures (e.g., shrouds) that would act to constrain the fish within a path through the turbine blades. This fact largely increases the likely avoidance rate as observed in laboratory tests and, in turn, increases the survival rate even more. Nevertheless, this conclusion may differ for other MHK designs in which the turbines are enclosed or in which flow contraction is enhanced to achieve greater availability of flow kinetic energy.

Ultimately, we can observe that for the small, juvenile salmonids considered in the analysis, similar survival rate outcomes can be obtained with a much simpler evaluation method if locations specific results are not needed. 
Table 4.4. Survival rate from the simulation cases, $\%$

\begin{tabular}{|l|c|c|c|c|}
\hline & & \multicolumn{3}{|c|}{ Kinematic SR (A), Fish size } \\
\hline$U_{\text {stream }}$ & TSR & Small & Mid & Large \\
\hline 1 & 8.00 & 98.3 & 87.2 & 79.1 \\
2 & 4.00 & 99.2 & 93.6 & 83.4 \\
3 & 2.67 & 99.4 & 95.7 & 88.9 \\
\hline & & \multicolumn{3}{|c|}{ Kinematic SR (B), Fish size } \\
\hline$U_{\text {stream }}$ & TSR & Small & Mid & Large \\
\hline 1 & 8.00 & 98.9 & 91.8 & 83.4 \\
2 & 4.00 & 99.5 & 95.9 & 89.4 \\
3 & 2.67 & 99.6 & 97.3 & 92.9 \\
\hline & & Lagrangian Solution SR, Particle size \\
\hline$U_{\text {stream }}$ & TSR & Small & Mid & Large \\
\hline 1 & 8.00 & 99.0 & 97.7 & 96.7 \\
2 & 4.00 & 99.4 & 98.6 & 98.1 \\
3 & 2.67 & 99.3 & 98.9 & 98.1 \\
\hline
\end{tabular}




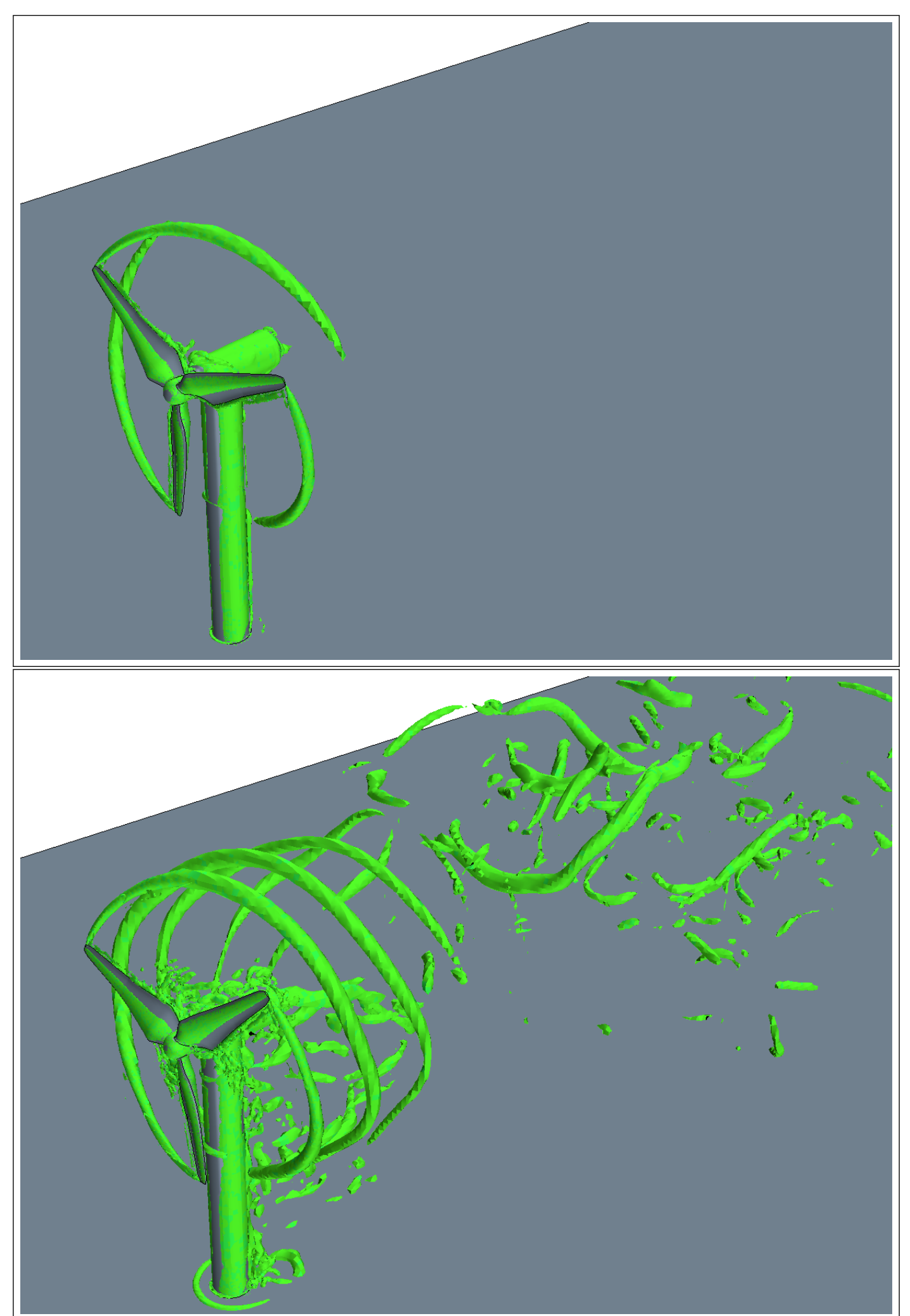

Figure 4.2. Iso-surfaces of Q-criterion equal to 8.0 shows the vortex structures that form in
the proximity of the MHK turbine, based upon a URANS (top) and DES (bottom) turbulence modeling approach 

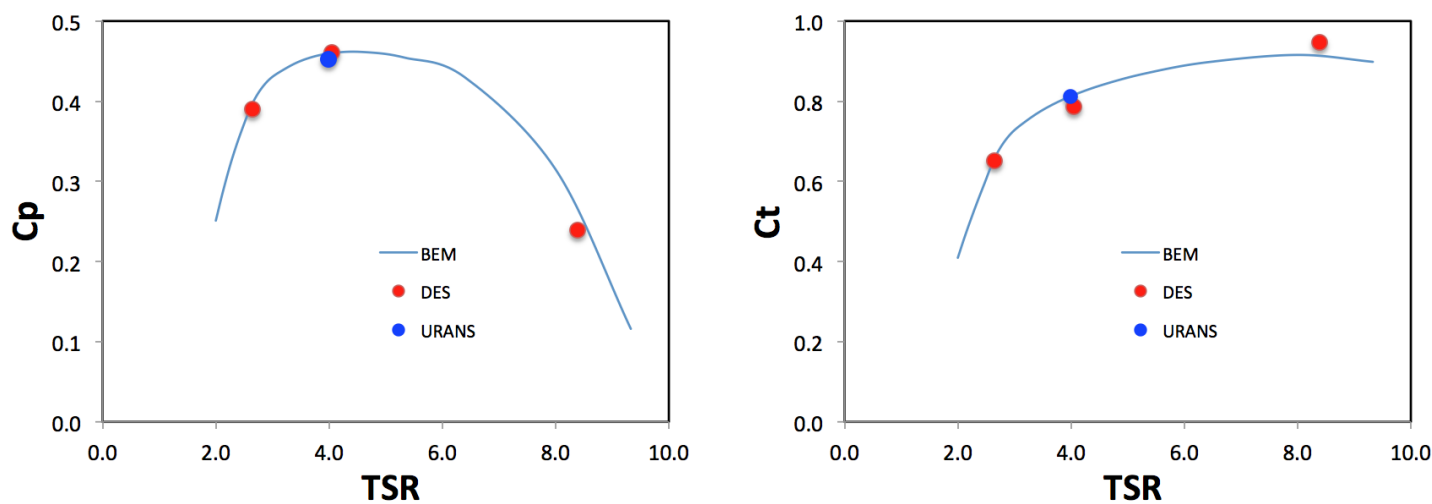

Figure 4.3. Power (left) and thrust (right) coefficients from BEM theory and CFD simulations 

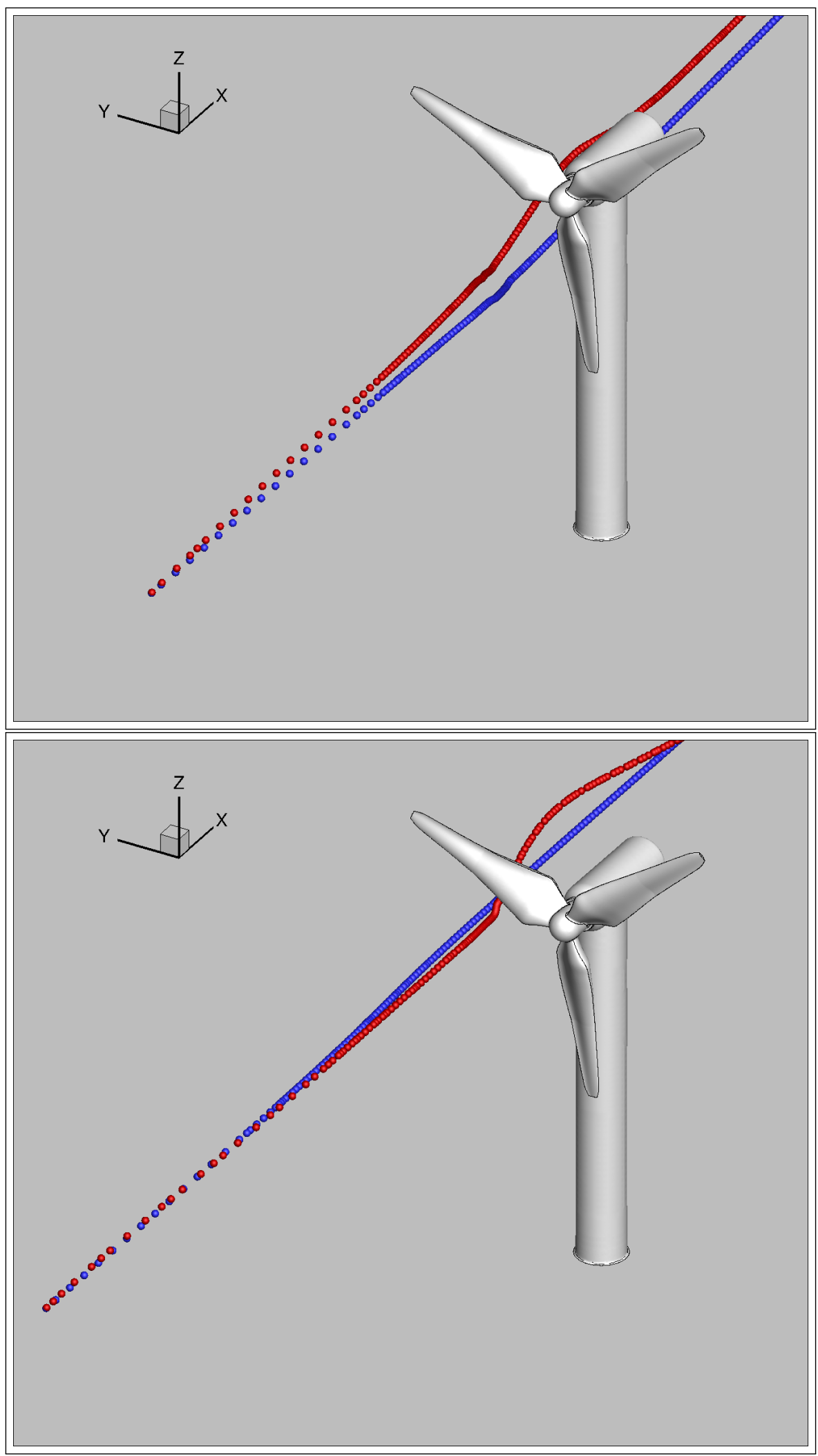

Figure 4.4. Particle tracks originating from the same injector and resulting from URANS (blue) and DES (red) turbulence simulations 


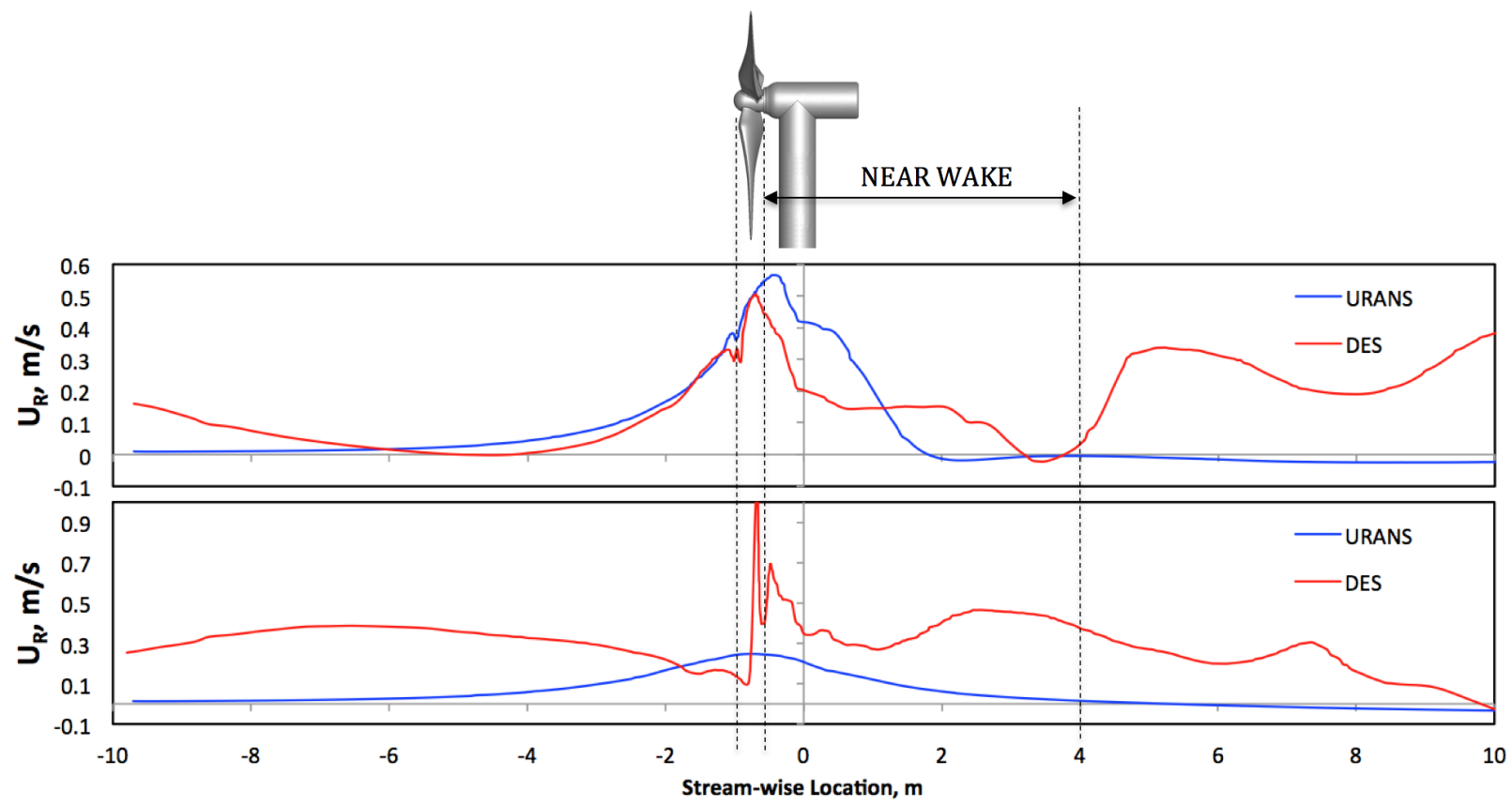

Figure 4.5. The change in particle location on a YZ-plane as it travels downstream. Particles correspond to those in frames of Figure 4.4. DES turbulence induces more rapid and continuous track changes in comparison to the URANS modeling approach 

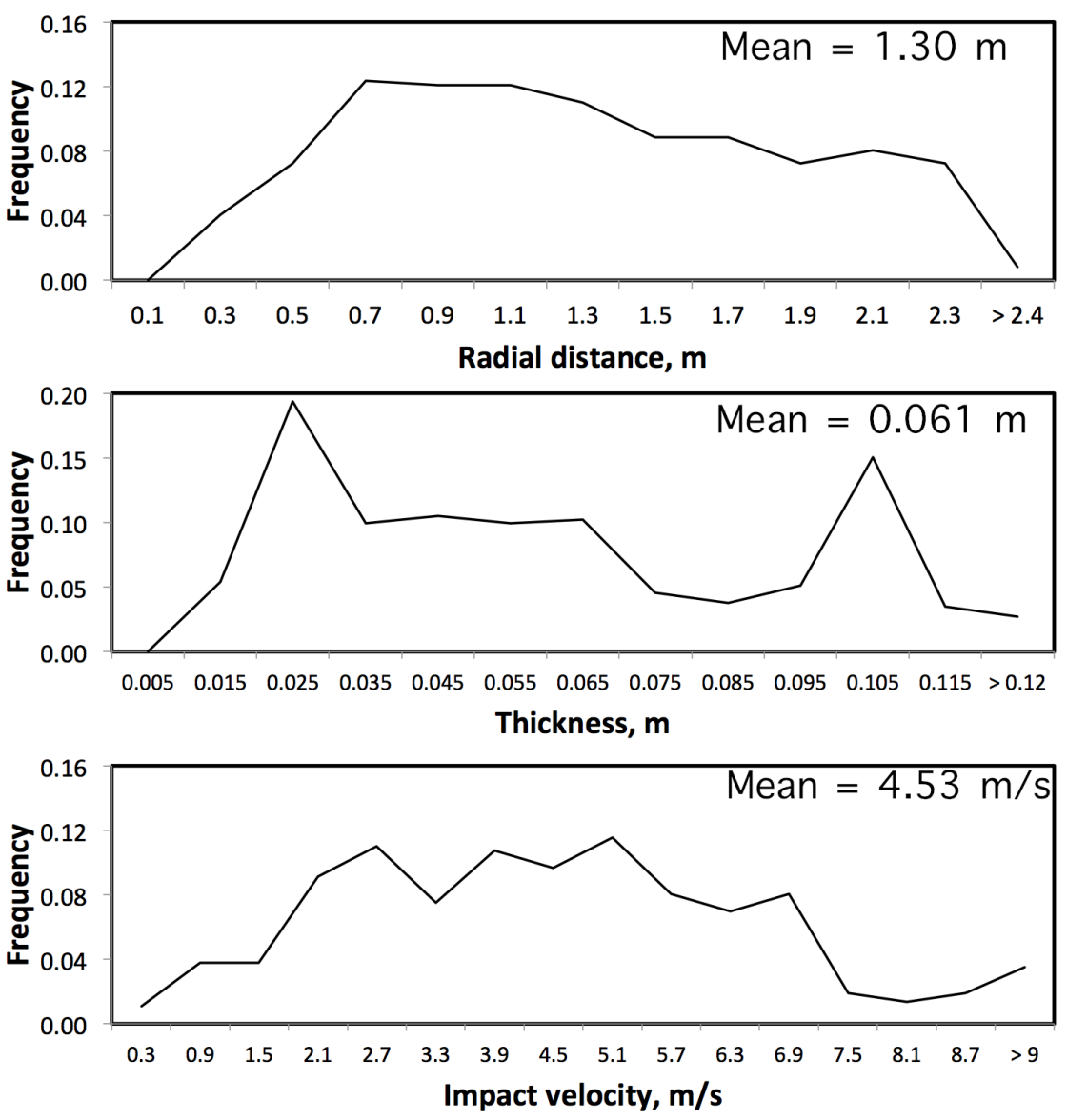

Figure 4.6. Frequency distribution of radial location (top), blade thickness (middle), and impact velocity for colliding particles of mid-size at $2 \mathrm{~m} / \mathrm{s}$ approach velocity 

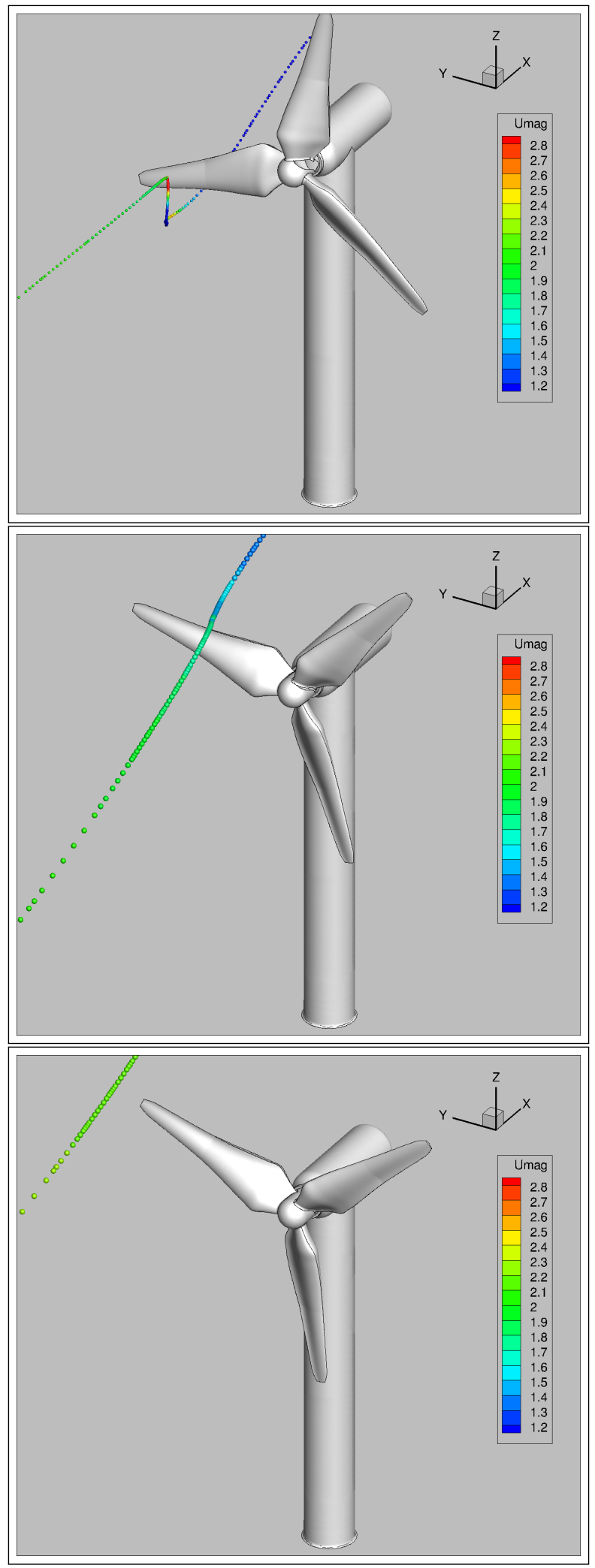

Figure 4.7. Three modes of Lagrangian particle interaction with the rotating blades: collision (top), potential but no collision (middle), and avoidance (bottom). The example particles were subject to a DES-simulated flow at $U_{\text {stream }}=2 \mathrm{~m} / \mathrm{s}$ 



\subsection{Summary and Future Work}

We conducted quantitative evaluations of the likelihood of blade-strike on a marine hydrokinetic turbine of the axial-flow type. The calculations used a method that involves the detailed solution of turbulent flow in combination with Lagrangian particle tracks to mimic potential fish pathways albeit not including volitional fish behavior such as avoidance. This novel method represents an improvement over typical environmental performance assessments and modeling because it combines the following components: (i) advanced turbulence modeling (DES), (ii) implementation of field-data-supported turbulent ambient inflow (SEM), (iii) transient blade-strike sampling on rotating turbine blades (rigid body motion, RBM), and (iv) movement of spheres with mass similar to fish (Lagrangian particle analysis). The proposed method allowed us to test the influence of three conditions on the likelihood of blade strike: the turbulent environment, the approaching inflow conditions, and the fish particle sizes. Additionally, we conducted the biological performance of blade strike probability by means of a conventional method that took into account the kinematic motion of objects through the turbine rotor plane. By using the same MHK design and flow conditions, we compared and discussed the results obtained from applying both methodologies.

By using a set of laboratory experimental correlations of exposure-response of live fish colliding on moving blades, the occurrence, frequency and intensity of the particle collisions were next used to calculate the survival rate of fish crossing the MHK turbine. This step indicated a low mortality rate $(<4 \%)$ which is consistent with experimental observations.

A detailed particle tracking analysis is currently underway in order to characterize the statistical distributions of strike/collision frequency, severity, and location, i.e. to better assess the potential consequences of the blade-strike events. For the future work, we will:

- Conduct statistical analysis of particle dispersion and redistribution in order to establish causal relationships between the flow environment and the likelihood of blade-strike

- Expand the present analysis to include other biological responses of fish (injury, mortality, etc) to the exposure to adverse flow conditions (strike, low pressure, turbulence, etc.)

- Incorporate the effect of fish distribution and cognitive behavior (e.g., avoidance) in the particle model using methods such as those prescribed by (Scheibe and Richmond 2002). 



\subsection{References}

Amaral S and G Hecker. 2008. Evaluation of the Effects of Turbine Blade Leading Edge Design on Fish Survival. 1014937, Electric Power Research Institute.

Amaral S, G Hecker, and N Pioppi. 2011a. Fish passage through turbines: application of conventional hydropower data to hydrokinetic technologies. 1024638, EPRI (Electric Power Research Institute).

Amaral S, N Perkins, D Giza, and B McMahon. 2011b. Evaluation of fish injury and mortality associated with hydrokinetic turbines. 1024569, EPRI (Electric Power Research Institute).

Bahaj A and L Myers. 2003. "Fundamentals applicable to the utilisation of marine current turbines for energy production." RENEWABLE ENERGY 28(14):2205-2211.

Batten W, A Bahaj, A Molland, and J Chaplin. 2006. "Hydrodynamics of marine current turbines." RENEWABLE ENERGY 31(2):249-256. 8th World Renewable Energy Congress and Expo, Denver, CO, AUG 29-SEP 03, 2004.

Castro-Santos T and A Haro. 2012. Survival and behavior of juvenile Atlantic salmon and adult American shad on exposure to a hydrokinetic turbine. 1026904, Electric Power Research Institute.

CD-adapco. 2013. User Guide, STAR-CCM+Version 8.02. CD-adapco, http://www.cdadapco.com.

Churchfield MJ, Y Li, and PJ Moriarty. 2013. "A large-eddy simulation study of wake propagation and power production in an array of tidal-current turbines." PHILOSOPHICAL TRANSACTIONS OF THE ROYAL SOCIETY A-MATHEMATICAL PHYSICAL AND ENGINEERING SCIENCES 371(1985, SI).

Dauble D, Z Deng, M Richmond, R Moursund, T Carlson, C Rakowski, and J Duncan. 2007. Biological Assessment of the Advanced Turbine Design at Wanapum Dam, 2005. PNNL-16682, Pacific Northwest National Laboratory, Richland, WA.

Escauriaza C and F Sotiropoulos. 2011. "Lagrangian model of bed-load transport in turbulent junction flows.” JOURNAL OF FLUID MECHANICS 666:36-76.

Gorlov A. 2010. Helical turbine and fish safety. Half-moon Cove Tidal Power Project P-12704, Tidewalker Associates.

Harrison ME, WMJ Batten, and AS Bahaj. 2010. "A Blade Element Actuator Disc Approach Applied to Tidal Stream Turbines." In OCEANS 2010, OCEANS-IEEE. IEEE; Marine Technol; OES. Washington State Conference and Trade Center (WSCTC), Seattle, WA, SEP 20-23, 2010.

Hunt J, A Wray, and P Moin. 1988. "Eddies, Streams, and Convergence Zones in Turbulent Flows." In Proceedings of the Summer Program 1988. Center for Turbulence Research. Stanford, CA. 
James SC, E Seetho, C Jones, and J Roberts. 2010. "Simulating Environmental Changes Due to Marine Hydrokinetic Energy Installations." In OCEANS 2010, OCEANS-IEEE. IEEE; Marine Technol; OES. Washington State Conference and Trade Center (WSCTC), Seattle, WA, SEP 20-23, 2010.

Jarrin N, S Benhamadouche, D Laurence, and R Prosser. 2006. "A synthetic-eddy-method for generating inflow conditions for large-eddy simulations." INTERNATIONAL JOURNAL OF HEAT AND FLUID FLOW 27(4):585-593. 4th International Symposium on Turbulence and Shear Flow Phenomena, Williamsburg, VA, JUN 27-29, 2005.

Kang S, I Borazjani, JA Colby, and F Sotiropoulos. 2012. "Numerical simulation of 3D flow past a real-life marine hydrokinetic turbine." ADVANCES IN WATER RESOURCES 39:33-43.

Lago LI, FL Ponta, and L Chen. 2010. “Advances and trends in hydrokinetic turbine systems." ENERGY FOR SUSTAINABLE DEVELOPMENT 14(4):287-296.

Mukherji SS, N Kolekar, A Banerjee, and R Mishra. 2011. "Numerical investigation and evaluation of optimum hydrodynamic performance of a horizontal axis hydrokinetic turbine." JOURNAL OF RENEWABLE AND SUSTAINABLE ENERGY 3(6).

Normandeau Associates I. 2009. An estimation of survival and injury of fish passed through the Hydro Green Energy Hydrokinetic System, and a characterization of fish entrainment potential at the Mississippi Lock and Dam No. 2 Hydroelectric Project (P-4306), Hastings, MN. Project No. 21288, Normandeau Associates, Inc.

Richmond M, J Serkowski, L Ebner, M Sick, R Brown, and T Carlson. 2013a. "Quantifying Barotrauma Risk to Juvenile Fish during Hydro-turbine Passage." In Review.

Richmond M, J Serkowski, C Rakowski, B Strickler, M Weisbeck, and C Dotson. 2013b. "Design Tools to Assess Hydro-Turbine Biological Performance: Priest Rapids Dam Turbine Replacement Project." In HydroVision 2013: Proceedings of the HydroVision International Conference. PennWell, Tulsa, OK.

Richmond MC, V Durgesh, J Thomson, and B Polagye. 2011. Inflow Characterization for Marine and Hydrokinetic Energy Devices. FY-2010 Annual Progress Report. PNNL-19859, Pacific Northwest National Laboratory.

Savoy T. 2007. "Prey eaten by Atlantic sturgeon in Connecticut waters." In American Fisheries Society Symposium, Vol. 56, pp. 157-165. American Fisheries Society.

Scheibe TD and MC Richmond. 2002. "Fish individual-based numerical simulator (FINS): a particle-based model of juvenile salmonid movement and dissolved gas exposure history in the Columbia River basin." Ecological Modelling 147(3):233-252.

Schwartz FJ. 1997. "Status of the Atlantic sturgeon, Acipenser oxyrinchus (PISCES, ACIPENSERIDAE) in North Carolina." The Journal of the Elisha Mitchell Scientific Society 113(2):46-52.

Schweizer PE, GF Cada, and MS Bevelhimer. 2011. Estimation of the risks of collision or strike to freshwater aquatic organisms resulting from operation of instream hydrokinetic turbines. $F Y$ 2010 Annual Progress Report. ORNL/TM-2011/133, Oak Ridge National Laboratory. 
Shiu H, C van Dam, M Barone, E Johnson, R Phillips, W Straka, A Fontaine, and M Jonson. 2012. "A Design of a Hydrofoil Family for Current-Driven Marine Hydrokinetic Turbines." In ICONE20, ICONE20POWER. Anaheim, CA, JUL 30 - AUG 3, 2012.

Spalart PR. 2009. "Detached-Eddy Simulation." ANNUAL REVIEW OF FLUID MECHANICS 41:181-202.

Thomson J, B Polagye, V Durgesh, and MC Richmond. 2012. "Measurements of Turbulence at Two Tidal Energy Sites in Puget Sound, WA." IEEE JOURNAL OF OCEANIC ENGINEERING 37(3):363-374.

Turnpenny A, S Clough, K Hanson, R Ramsay, and D McEwan. 2000. Risk Assessment for Fish Passage through Small, Low-Head Turbines. ETSU H/06/0054/REP, Prepared by Fawley Aquatic for ETSU.

von Raben K. 1957. "Regarding the problem of mutilations of fishes by hydraulic turbines." Die Wasserwirtschaft 4:97-100.

Wang M, CH Lin, and Q Chen. 2012. “Advanced turbulence models for predicting particle transport in enclosed environments." BUILDING AND ENVIRONMENT 47:40-49. 


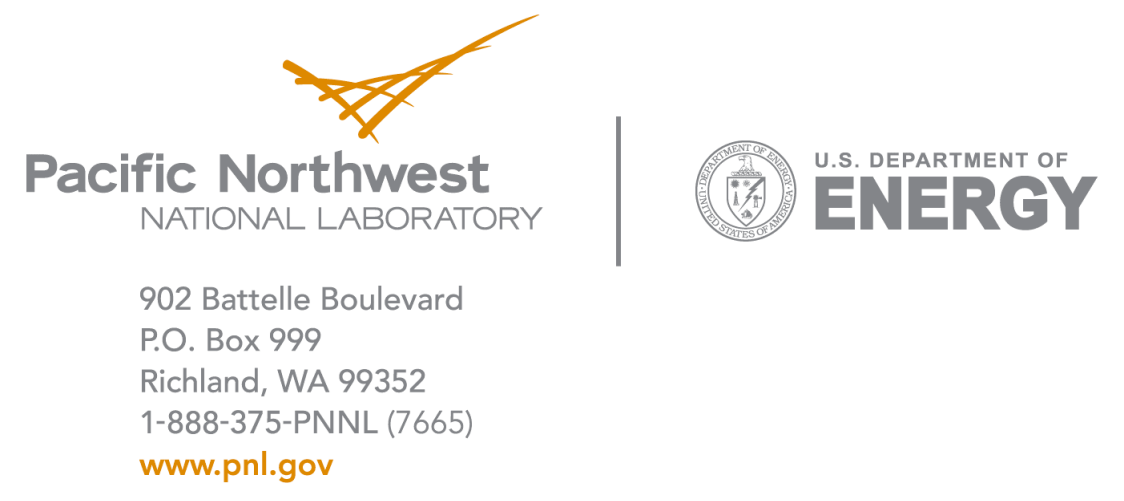

